\title{
A Survey on Banknote Recognition Methods by Various Sensors
}

\author{
Ji Woo Lee, Hyung Gil Hong, Ki Wan Kim and Kang Ryoung Park* \\ Division of Electronics and Electrical Engineering, Dongguk University, 30 Pildong-ro 1-gil, Jung-gu, \\ Seoul 100-715, Korea; ljwgs@dongguk.edu (J.W.L.); hell@dongguk.edu (H.G.H.); \\ yawara18@hotmail.com (K.W.K.) \\ * Correspondence: parkgr@dongguk.edu; Tel.: +82-10-3111-7022; Fax: +82-2-2277-8735 \\ Academic Editor: Vittorio M. N. Passaro \\ Received: 5 January 2017; Accepted: 4 February 2017; Published: 8 February 2017
}

\begin{abstract}
Despite a decrease in the use of currency due to the recent growth in the use of electronic financial transactions, real money transactions remain very important in the global market. While performing transactions with real money, touching and counting notes by hand, is still a common practice in daily life, various types of automated machines, such as ATMs and banknote counters, are essential for large-scale and safe transactions. This paper presents studies that have been conducted in four major areas of research (banknote recognition, counterfeit banknote detection, serial number recognition, and fitness classification) in the accurate banknote recognition field by various sensors in such automated machines, and describes the advantages and drawbacks of the methods presented in those studies. While to a limited extent some surveys have been presented in previous studies in the areas of banknote recognition or counterfeit banknote recognition, this paper is the first of its kind to review all four areas. Techniques used in each of the four areas recognize banknote information (denomination, serial number, authenticity, and physical condition) based on image or sensor data, and are actually applied to banknote processing machines across the world. This study also describes the technological challenges faced by such banknote recognition techniques and presents future directions of research to overcome them.
\end{abstract}

Keywords: banknote recognition; counterfeit banknote detection; serial number recognition; fitness classification; various sensors

\section{Introduction}

\subsection{Motivation of the Research}

Despite a decrease in the use of currency due to the recent global expansion in electronic financial transactions, transactions in real money continue to be very important in the global market [1]. While performing transactions in real money, touching and counting notes by hand is still a common practice in daily life, but the use of various types of automated machines has become essential for large-scale and safe transactions. Such automated self-service machines include automated teller machines (ATMs) for money deposits and withdrawals, as well as financial transactions [2], banknote counters [3] and coin counters [4], mostly used in banks, and automatic vending machines, into which money is inserted to purchase goods [5]. These devices must be equipped with four essential functions: banknote recognition, counterfeit banknote detection, serial number recognition, and fitness classification. While limited surveys have been conducted in previous studies on the areas of banknote recognition and counterfeit banknote recognition, this paper is the first survey of its kind to review all four areas. This lack of research is ascribable to the fact that banknote recognition studies have been mostly carried out in industrial settings rather than for academic purposes. In this study, 
previous studies and the advantages and disadvantages of the different methods related to the four aforementioned areas used therein are analyzed, and future applications are also presented.

\subsection{Scope and Method of Our Research}

\subsubsection{Scope of Our Research}

This paper presents methodologies for recognizing banknotes in the four main categories of banknote recognition, counterfeit banknote detection, serial number recognition, and fitness classification.

Banknote recognition generally concerns classification of banknotes by denomination, i.e., the currency amount of a note of a specific country. This classification also enables recognition of the year of printing and input direction of the classified denomination. In some studies, the scope of recognition is extended to simultaneous recognition of two or more national currencies. Technologies for banknote recognition are described in detail in Section 2.

Counterfeit banknote detection generally concerns methods for distinguishing between genuine and fake notes. As shown in the example of a genuine and a counterfeit USD 100 bill in Figure 1a,b, respectively, a validation check is done by examining anti-counterfeiting features. Section 3 describes technologies for counterfeit banknote detection in detail.

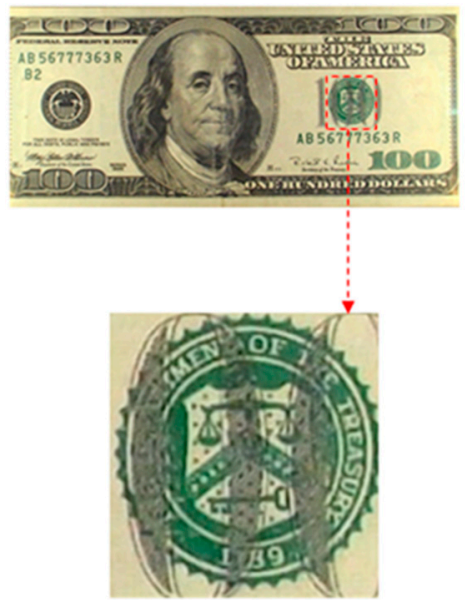

(a)

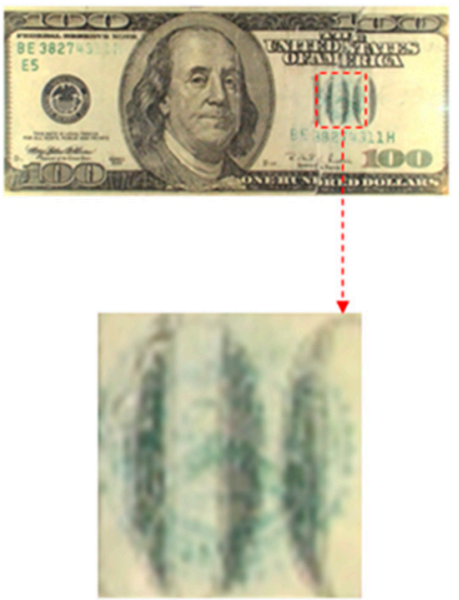

(b)

Figure 1. Example of genuine and counterfeit banknotes (USD 100 bill): (a) a genuine banknote; (b) a counterfeit banknote.

A banknote serial number is a unique alphanumerical identifier engraved on each banknote in the banknote production process. It contains the name of the issuing bank and serial information of each denomination [6]; Figure 2 shows the serial number of a USD 100 bill. Since each banknote has its own unique serial number, it can be used to trace its source and circulation route and can thus be efficiently used to detect counterfeit banknotes. Related technologies are described in detail in Section 4.

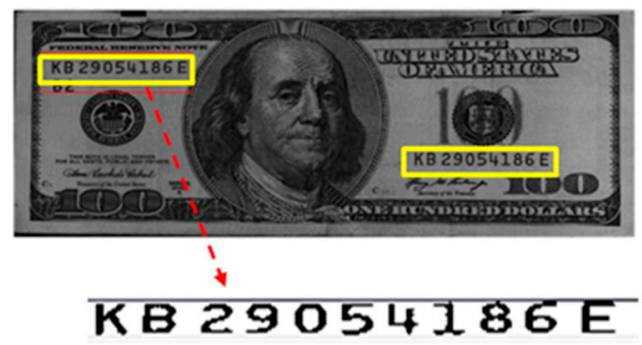

Figure 2. Example of serial number code (USD 100 bill). 
Fitness classification of banknotes generally concerns methods for classifying banknotes according to their physical conditions, such as soiling. As shown in the example of two INR 10 bills in Figure 3, banknotes of the same denomination may exhibit fit or unfit conditions, which include soiling and creases (Figure 3a), depending on circulation intensity and climate conditions. In order to maintain the fitness of banknotes in circulation, automated self-service terminals, such as ATMs, need to be equipped with a fitness classification function to sort out and retrieve unfit banknotes. Retrieving unfit banknotes is also necessary for preventing banknote classification errors. Fitness classification-related technologies are described in detail in Section 5.

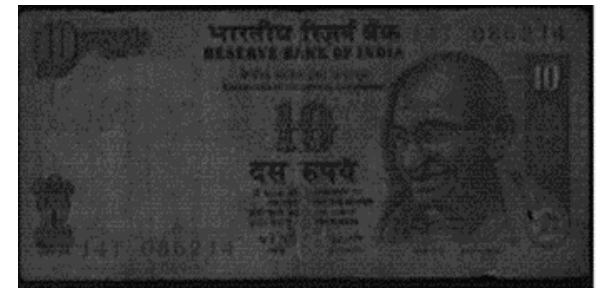

(a)

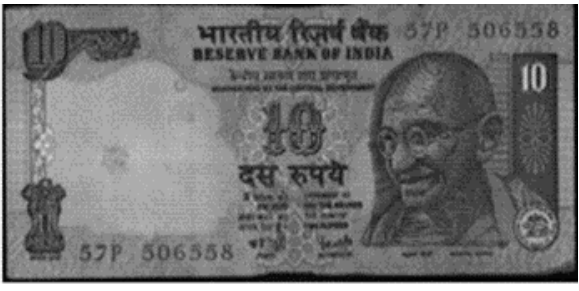

(b)

Figure 3. Example of unfit and fit banknotes (INR 10 bill): (a) Unfit banknote; (b) Fit banknote.

\subsubsection{Method of Our Research}

Figure 4 presents a typical process flow of banknote recognition implemented in a self-service terminal. An input banknote is scanned by a sensor to discern the image and other data necessary for recognizing its denomination and anti-counterfeiting features. The first step in the process of banknote recognition is identifying the denomination of an input banknote, thereby clustering all classes into a single class, and implementing a size-based (1) validation check, followed by (1) banknote recognition on the class of notes identified as banknotes, (3) counterfeit banknote detection using anti-counterfeiting data specific to each recognized denomination, and (4) fitness classification. The flow direction of (2) serial number recognition is determined depending on the counterfeit banknote detection method as shown in Figure 4. System efficiency is the main reason for setting the process flow direction as (1) validation check and banknote recognition, then (3) counterfeit banknote detection, and finally (4) fitness classification. For example, any input materials other than banknotes to be classified, such as common paper and newspaper, are sorted out at the (1) validation check step, obviating the later steps of (3) counterfeit banknote detection, (2) serial number recognition, and (4) fitness classification. On the other hand, an input counterfeit banknote similar to the classified banknote [7] may pass through the banknote recognition step, but will likely be detected as counterfeit in the counterfeit banknote detection step implemented using anti-counterfeiting features specific to the denomination classified, which makes the steps of serial number recognition (case 2 in Figure 4) and fitness classification superfluous.

In a common embedded system environment, such as a banknote counter, rapid real-time recognition processing is required so that it can be implemented concurrently with banknote counting. When performing counterfeit banknote detection, for example, unnecessary computation should be excluded to rapidly process the banknotes queued for input. There are also cases in which steps such as serial number recognition and fitness classification need to be processed in the on/off mode to enhance the computational flow efficiency. Taking into account such processing paths, most automated currency recognition machines use the processing algorithm presented in Figure 4. Therein, however, the (2) serial number recognition processing step can be bifurcated (case 1 or 2) depending on whether the serial number information is used for counterfeit banknote detection or not. If the serial number information is used for counterfeit banknote detection (case 1), the input banknote goes through the steps of serial number recognition for the corresponding denomination and counterfeit banknote detection. On the contrary, if the serial number information is not used for the counterfeit banknote 
detection (case 2), the time-consuming serial number recognition operation can be performed after the counterfeit banknote detection step, thus reducing the time taken for counterfeit banknote detection. As regards the serial number recognition and fitness classification functions, given their less important roles compared to the banknote recognition and counterfeit banknote detection functions, they could be removed from the main computational flow and processed in the on/off mode. In the off mode of the serial number recognition and fitness classification functions, the user can perform the computations for counterfeit banknote detection more rapidly. This method of enabling the off mode of the serial number recognition and fitness classification functions can be essential for a banknote counter that carries out real-time computations of over 1000 notes per minute to perform rapid counterfeit detection.

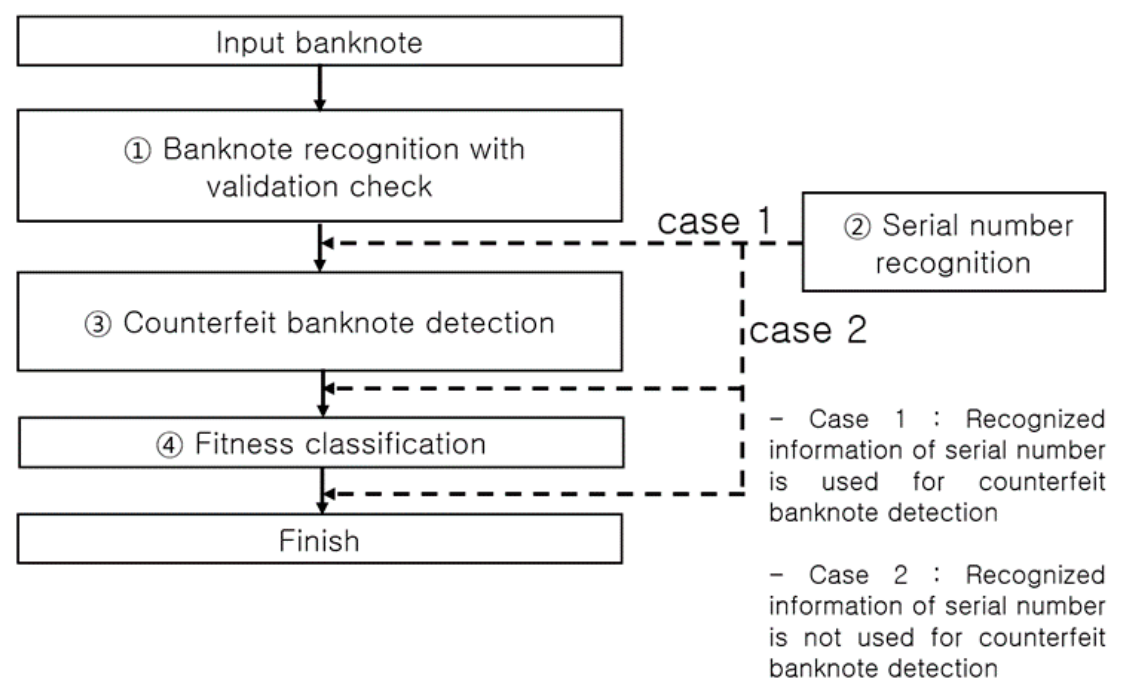

Figure 4. Banknote recognition process flow in an automated device.

Section 2 describes the aforementioned image-based banknote recognition methods. Section 3 describes counterfeit banknote detection of the recognized denomination on the basis of the obtained image and sensor data (ultra violet (UV), near-infrared (NIR), etc.). Section 4 describes methods for image-based serial number recognition of a denomination, and Section 5 describes image-based fitness classification of the soiled condition of a denomination recognized as a genuine banknote. Lastly, Section 6 presents methodologies employing the described banknote recognition technologies and areas for further study and future directions.

\section{Banknote Recognition}

\subsection{Banknote Recognition Methodology}

Banknote recognition is a process step in which the denomination (e.g., \$1, \$10 and \$100), direction (e.g., forward or backward direction), and side (e.g., obverse or reverse side) of the input banknote are classified. The reason for classifying direction and side in addition to denomination is that the position of a region of interest (ROI) within a banknote, which is used to implement the later process steps (serial number recognition, counterfeit banknote detection, and fitness classification), changes according to the direction and side of the banknote, as shown in Figure 5. For example, if the ROI of a $\$ 1$ bill is in the top-left corner of its image when input in the forward direction, the position changes to the bottom-right corner when input in the backward direction. Moreover, the function of an automated machine of classifying input banknotes by denomination, direction, and side is essential for a bank employee to manually check the automatically classified banknotes.

Most conventional sensors for banknote recognition are visible-light line sensors, such as contact image sensors (CIS) [8-13]. Such sensors mostly obtain color or black-and-white images and are 
used for the typical process flow of (1) preprocessing, (2) feature extraction, (3) classification, and (4) verification, as shown in Figure 5. Using a color image sensor is more advantageous because it provides more information than a black-and-white sensor [14], but its production cost is higher. Besides image resolution, national currencies and classification criteria are factors influencing the efficiency of banknote recognition.

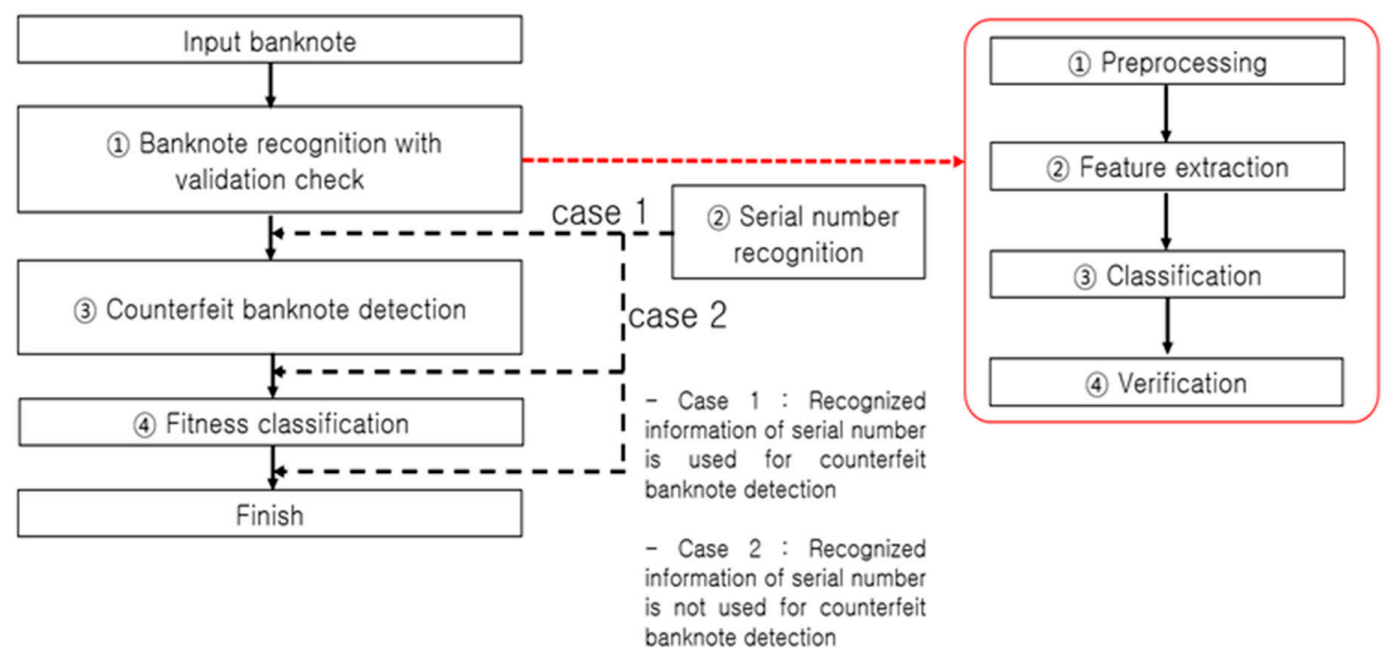

Figure 5. Banknote recognition process flow.

Table 1 lists previous studies on banknote recognition of various national currencies. In this table, "N/I" means the case that the appropriate information is not provided in the paper. " $\mathrm{A}$ " represents the case that the database is available for research purpose whereas "N/A" shows the case that the database is not available. USD, CNY, INR, and EUR are the most frequently studied currencies. In Table 1, the largest numbers of images are included in the database of [11]. Most databases are not available, except for that described in [14].

Table 1. Studies on banknote recognition by national currency (Ref.: Reference(s), N/I: No Information, A: Available, N/A: Not Available).

\begin{tabular}{|c|c|c|c|c|c|c|}
\hline \multirow{2}{*}{$\begin{array}{l}\text { Recognition } \\
\text { Mode }\end{array}$} & \multirow{2}{*}{$\begin{array}{l}\text { National } \\
\text { Currency }\end{array}$} & \multirow{2}{*}{ References } & \multicolumn{3}{|c|}{ Databases } & \multirow{2}{*}{$\begin{array}{l}\text { Availability } \\
\text { of Database }\end{array}$} \\
\hline & & & Ref. & \#Images & $\begin{array}{l}\text { \#Denomination } \\
\text { Kind }\end{array}$ & \\
\hline \multirow{13}{*}{$\begin{array}{c}\text { Single } \\
\text { Currency } \\
\text { Recognition }\end{array}$} & \multirow{5}{*}{$\begin{array}{l}\text { United States } \\
\text { (USD) }\end{array}$} & \multirow{5}{*}[8,9,15-25]{} & [8] & 61,240 & 16 & N/A \\
\hline & & & [9] & 99,236 & 17 & N/A \\
\hline & & & {$[15,22]$} & 3570 & 6 & $\mathrm{~N} / \mathrm{A}$ \\
\hline & & & [16] & 15,000 & 6 & N/A \\
\hline & & & [19] & 65,700 & 12 & N/A \\
\hline & \multirow{5}{*}{ China (CNY) } & \multirow{5}{*}[11-13,16,26-31]{} & [11] & 297,200 & 3 & $\mathrm{~N} / \mathrm{A}$ \\
\hline & & & [13] & 16,000 & 5 & N/A \\
\hline & & & [26] & 3360 & 4 & $\mathrm{~N} / \mathrm{A}$ \\
\hline & & & [28] & 20,000 & 5 & $\mathrm{~N} / \mathrm{A}$ \\
\hline & & & [30] & 1600 & 4 & $\mathrm{~N} / \mathrm{A}$ \\
\hline & \multirow{3}{*}{ Euro (EUR) } & \multirow{3}{*}[16,32-35]{} & [16] & 15,000 & 7 & $\mathrm{~N} / \mathrm{A}$ \\
\hline & & & [32] & 140 & 7 & $\mathrm{~N} / \mathrm{A}$ \\
\hline & & & [35] & 82 & $\mathrm{~N} / \mathrm{I}$ & $\mathrm{N} / \mathrm{A}$ \\
\hline
\end{tabular}


Table 1. Cont.

\begin{tabular}{|c|c|c|c|c|c|c|}
\hline \multirow{2}{*}{$\begin{array}{l}\text { Recognition } \\
\text { Mode }\end{array}$} & \multirow{2}{*}{$\begin{array}{l}\text { National } \\
\text { Currency }\end{array}$} & \multirow[b]{2}{*}{ References } & \multicolumn{3}{|c|}{ Databases } & \multirow{2}{*}{$\begin{array}{l}\text { Availability } \\
\text { of Database }\end{array}$} \\
\hline & & & Ref. & \#Images & $\begin{array}{l}\text { \#Denomination } \\
\text { Kind }\end{array}$ & \\
\hline \multirow{25}{*}{$\begin{array}{c}\text { Single } \\
\text { Currency } \\
\text { Recognition }\end{array}$} & \multirow{3}{*}{ India (INR) } & \multirow{3}{*}{ [36-43] } & [36] & 350 & 7 & $\mathrm{~N} / \mathrm{A}$ \\
\hline & & & [38] & 39 & 3 & $\mathrm{~N} / \mathrm{A}$ \\
\hline & & & [41] & 504 & 6 & $\mathrm{~N} / \mathrm{A}$ \\
\hline & $\begin{array}{l}\text { South Korea } \\
\text { (KRW) }\end{array}$ & \multicolumn{2}{|l|}{ [44] } & 10,800 & 3 & $\mathrm{~N} / \mathrm{A}$ \\
\hline & \multirow{3}{*}{ Iran (IRR) } & \multirow{3}{*}[45-48]{} & [45] & 4000 & 8 & $\mathrm{~N} / \mathrm{A}$ \\
\hline & & & [47] & 128 & 8 & N/A \\
\hline & & & [48] & 240 & 6 & $\mathrm{~N} / \mathrm{A}$ \\
\hline & Mexico (MXN) & \multicolumn{2}{|l|}{$[49,50]$} & 1600 & 5 & $\mathrm{~N} / \mathrm{A}$ \\
\hline & Australia (AUD) & {$[51,52]$} & [51] & 1320 & 6 & $\mathrm{~N} / \mathrm{A}$ \\
\hline & $\begin{array}{l}\text { South African } \\
\text { (ZAR) }\end{array}$ & \multicolumn{2}{|l|}{ [9] } & 760 & 10 & $\mathrm{~N} / \mathrm{A}$ \\
\hline & $\begin{array}{l}\text { New Zealand } \\
\text { (NZD) }\end{array}$ & \multicolumn{2}{|l|}{ [53] } & 367 & 5 & $\mathrm{~N} / \mathrm{A}$ \\
\hline & Sri Lanka (LKR) & \multicolumn{2}{|l|}{ [54] } & 280 & 4 & $\mathrm{~N} / \mathrm{A}$ \\
\hline & Pakistan (PKR) & \multicolumn{2}{|l|}{ [55] } & 120 & 6 & $\mathrm{~N} / \mathrm{A}$ \\
\hline & Angola (AOA) & \multicolumn{2}{|l|}{ [9] } & 1366 & 9 & $\mathrm{~N} / \mathrm{A}$ \\
\hline & \multirow[b]{2}{*}{ Italy (ITL) } & \multirow[b]{2}{*}{ [56-58] } & [57] & 80 & 8 & N/A \\
\hline & & & [58] & 30 & 8 & $\mathrm{~N} / \mathrm{A}$ \\
\hline & \multirow{3}{*}{$\begin{array}{l}\text { Saudi Arabia } \\
\text { (SAR) }\end{array}$} & \multirow{3}{*}[37,59,60]{} & [37] & 4 & 2 & $\mathrm{~N} / \mathrm{A}$ \\
\hline & & & [59] & 300 & 3 & $\mathrm{~N} / \mathrm{A}$ \\
\hline & & & [60] & 110 & 1 & $\mathrm{~N} / \mathrm{A}$ \\
\hline & Jordan (JOD) & \multicolumn{2}{|l|}{ [14] } & 500 & 10 & $\mathrm{~A}$ \\
\hline & Ethiopia (ETB) & \multicolumn{2}{|l|}{ [61] } & 240 & 5 & N/A \\
\hline & \multirow{2}{*}{$\begin{array}{l}\text { Bangladesh } \\
\text { (BDT) }\end{array}$} & \multirow{2}{*}[62,63]{} & [62] & 1700 & 8 & $\mathrm{~N} / \mathrm{A}$ \\
\hline & & & [63] & $\mathrm{N} / \mathrm{I}$ & 7 & $\mathrm{~N} / \mathrm{A}$ \\
\hline & $\begin{array}{l}\text { Myanmar } \\
\text { (MMK) }\end{array}$ & [64] & & 89 & 5 & $\mathrm{~N} / \mathrm{A}$ \\
\hline & Malawi (MWK) & [9] & & 2464 & 6 & $\mathrm{~N} / \mathrm{A}$ \\
\hline \multirow{7}{*}{$\begin{array}{l}\text { Multi-Currency } \\
\text { Simultaneous } \\
\text { Recognition }\end{array}$} & $\begin{array}{c}\text { USD, EUR, } \\
\text { KRW, CNY, } \\
\text { Russia (RUB) }\end{array}$ & [10] & & $\begin{array}{l}100,797 \text { from } \\
5 \text { national } \\
\text { currencies }\end{array}$ & $\begin{array}{l}55 \text { from } 5 \\
\text { national } \\
\text { currencies }\end{array}$ & $\mathrm{N} / \mathrm{A}$ \\
\hline & $\begin{array}{c}23 \text { countries } \\
\text { (CNY, EUR, INR, } \\
\text { USD, etc.) }\end{array}$ & [65] & & $\begin{array}{c}150 \text { from } 23 \\
\text { national } \\
\text { currencies }\end{array}$ & $\begin{array}{c}101 \text { from } 23 \\
\text { national } \\
\text { currencies }\end{array}$ & $\mathrm{N} / \mathrm{A}$ \\
\hline & $\begin{array}{l}\text { Turkey (TRY), } \\
\text { Cyprus (CYP) }\end{array}$ & [66] & & $\begin{array}{l}180 \text { (TRY), } \\
144 \text { (CYP) }\end{array}$ & $\begin{array}{l}5 \text { (TRY), } \\
4 \text { (CYP) }\end{array}$ & $\mathrm{N} / \mathrm{A}$ \\
\hline & USD, EUR & [67] & & $\mathrm{N} / \mathrm{I}$ & $\begin{array}{l}4 \text { (USD), } \\
7 \text { (EUR) }\end{array}$ & N/A \\
\hline & $\begin{array}{l}\text { USD, Japan } \\
\text { (JPY) }\end{array}$ & [68] & & $\begin{array}{c}132 \text { (USD), } \\
50 \text { (JPY) }\end{array}$ & $\begin{array}{l}6 \text { (USD), } \\
3 \text { (JPY) }\end{array}$ & $\mathrm{N} / \mathrm{A}$ \\
\hline & $\begin{array}{l}\text { JPY, ITL, Spain } \\
\text { (ESP), France } \\
\text { (FRF) }\end{array}$ & [69] & & $\begin{array}{l}165 \text { (JPY), } \\
440 \text { (ITL), } \\
385 \text { (ESP), } \\
275 \text { (FRF) }\end{array}$ & $\begin{array}{l}3 \text { (JPY), } \\
8 \text { (ITL), } \\
7 \text { (ESP), } \\
5 \text { (FRF) }\end{array}$ & N/A \\
\hline & $\begin{array}{l}\text { USD, EUR, BDT, } \\
\text { INR }\end{array}$ & [70] & & $\begin{array}{l}300 \text { (USD), } \\
300 \text { (EUR), } \\
500 \text { (BDT), } \\
300 \text { (INR) }\end{array}$ & $\begin{array}{l}3 \text { (USD), } \\
3 \text { (EUR), } \\
5 \text { (BDT), } \\
3 \text { (INR) }\end{array}$ & $\mathrm{N} / \mathrm{A}$ \\
\hline
\end{tabular}


A number of studies have also been conducted on simultaneous recognition of multiple national currencies. The number of classes to be classified increases with the number of national currencies to be simultaneously recognized, and the classification efficiency decreases with the increase in the number of the national currencies to which the same algorithm is applied. If a banknote counter can recognize notes with a speed exceeding 1000 notes per minute, a complicated system such as a multi-currency simultaneous recognition processing system requires a recognition algorithm optimized for accuracy and speed. It involves the process steps presented in Figure 5: (1) preprocessing: image preprocessing such as precise banknote region segmentation, optimal dimension reduction, and noise removal; (2) feature extraction: extraction of features best-suited for the classification of the given denomination; (3) classification: classification of the recognized denomination into classes using the extracted features and classifier; and (4) verification: recheck of the classified denomination).

\subsection{Preprocessing of Banknote Image}

Preprocessing of the images obtained through the sensor involves the following process steps: banknote region segmentation, as shown in Figure 6, to extract the precise denomination region [8], noise removal and gray level reduction, brightness normalization and contrast enhancement, and reduction of the image resolution and number of image channels to reduce the computational burden.

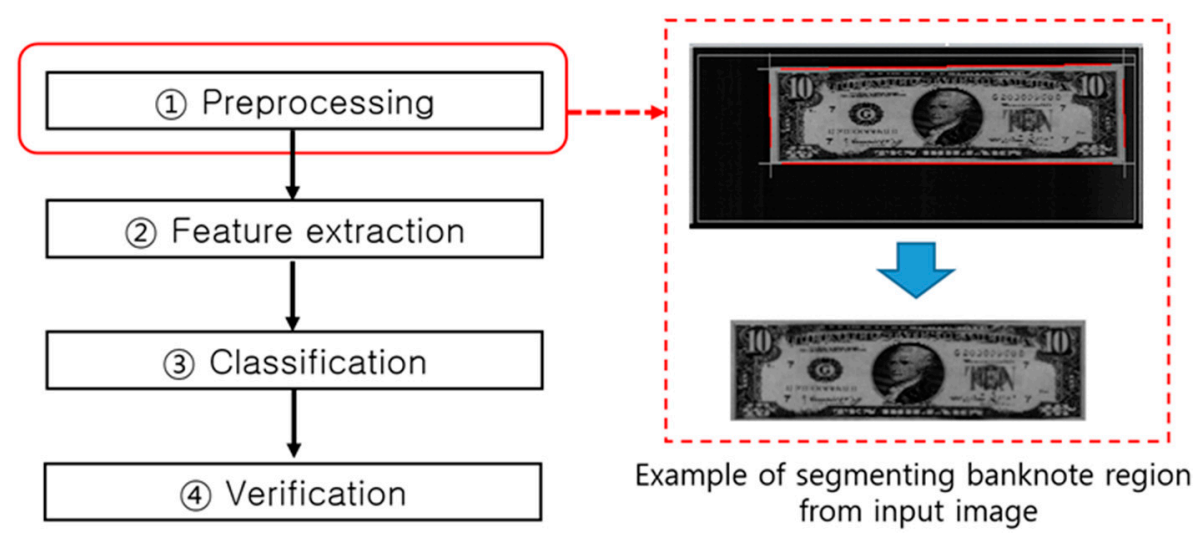

Figure 6. Preprocessing step in the banknote recognition process flow.

First of all, the banknote region segmentation algorithm is applied to extract the precise banknote region. Relevant methods include corner detection [8,9], least square methods and fuzzy systems [12], and component labeling using the $Y$ component of the YIQ color space via axis transformation [68] as shown in Table 2. If a banknote has been in circulation for a long time, it may be difficult to extract accurate banknote recognition features due to its surface being soiled by dirt and sebum from users' hands. To address this, noise removal is performed as a general preprocessing step using techniques based on the Wiener filter $[10,49,55,65,71]$ or median filter $[42,64]$. Noise occurring in the imaging process or banknote aging can also be diminished by reducing the gray level of the image beyond the $0-255$ range $[54,65,71,72]$. Some studies have presented methods to normalize the brightness and improve the contrast of the image by means of histogram equalization [42,45].

Finally, a data reduction process is performed in order to reduce the computational burden. As mentioned previously, this process is essential because of the limited memory and processing speed, although the larger the amount of information, the greater the performance. In general, image interpolation, e.g., the nearest neighbor interpolation method [10,67], is used to reduce image size. Furthermore, conversion from RGB to gray scale can be performed to reduce the color dimension $[23,39,46,55,63,72]$. 
Table 2. Methods for preprocessing in the banknote recognition process flow.

\begin{tabular}{|c|c|c|}
\hline Task & Method & References \\
\hline \multirow{3}{*}{ Banknote region segmentation } & Corner detection & {$[8,9]$} \\
\hline & Least square method and fuzzy system & [12] \\
\hline & $\begin{array}{l}\text { Component labeling based on the } \mathrm{Y} \\
\text { component of YIQ space }\end{array}$ & {$[68]$} \\
\hline \multirow{3}{*}{$\begin{array}{l}\text { Noise removal and gray } \\
\text { level reduction }\end{array}$} & Weiner filtering & {$[10,49,55,65,71]$} \\
\hline & Median filtering & {$[42,64]$} \\
\hline & Gray level reduction & {$[54,65,71,72]$} \\
\hline $\begin{array}{l}\text { Brightness normalization and } \\
\text { contrast enhancement }\end{array}$ & Histogram equalization & {$[42,45]$} \\
\hline Image resolution reduction & Nearest neighbor interpolation & {$[10,67]$} \\
\hline Image channel reduction & Conversion of color to gray & {$[23,39,46,55,63,72]$} \\
\hline
\end{tabular}

\subsection{Feature Extraction}

As shown in Figure 7, the preprocessed data undergoes feature extraction designed to facilitate the denomination classification. Figure 7 provides an example of an extracted similarity map expressing the feature regions for efficient classification.

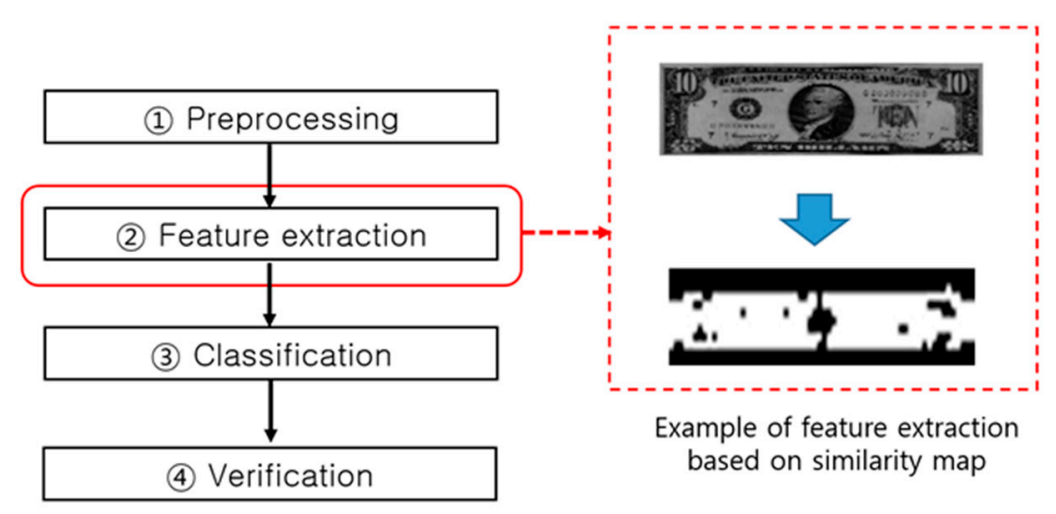

Figure 7. Feature extraction in the banknote recognition process flow.

Among the methods for extracting banknote features to classify denominations presented in Table 3 , those using the size or length data of a banknote as a parameter $[45,56,60,65,68,72]$ are especially useful for classifying national currencies with different sizes or lengths for different denominations. There are also methods using RGB, HSV, or features in the HSI color space $[37,40,45,49,50,61,68]$, methods using edge-based features expressed with Canny, Prewitt, or Sobel operators [40,44,54,60], and methods using histogram information-based features such as correlation, central moments, kurtosis, mean, standard deviation, and skewness [39,43,53,59,64,65].

Furthermore, there are methods that use texture features extracted by local binary patterns (LBP) [41,49] and features based on the values of the gray-level co-occurrence matrix (GLCM) [39,53,64]. Conventional methods of feature extraction widely used in the common pattern recognition fields, include methods using principle component analysis (PCA) $[8,9,15,20-23,26,46]$ and linear discriminant analysis (LDA) [43,46,70], and also methods using genetic algorithm (GA)-based learning to identify the feature mask optimized for the target class $[24,30,69,73]$. Similarity maps or difference maps are an automated optimal feature search method $[9,10,19]$. 
Table 3. Methods for feature extraction in the banknote recognition process flow.

\begin{tabular}{ll}
\hline \multicolumn{1}{c}{ Method } & \multicolumn{1}{c}{ References } \\
\hline Features of banknote size or length & {$[45,56,60,65,68,72]$} \\
\hline Color information (RGB, HSV, or HSI) & {$[37,40,45,49,50,61,68]$} \\
\hline Edge information (Canny, Prewitt, or Sobel operator) & {$[40,44,54,60]$} \\
\hline $\begin{array}{l}\text { Histogram information (correlation, central moments, kurtosis, } \\
\text { mean, standard deviation, skewness, etc.) }\end{array}$ & {$[39,43,53,59,64,65]$} \\
\hline Local binary patterns (LBP) & {$[41,49]$} \\
\hline Gray-level co-occurrence matrix (GLCM) & {$[39,53,64]$} \\
\hline Principle component analysis (PCA) & {$[8,9,15,20-23,26,46]$} \\
\hline Linear discriminant analysis (LDA) & {$[43,46,70]$} \\
\hline Genetic algorithm (GA) & {$[24,30,69,73]$} \\
\hline Similarity map or difference map & {$[9,10,19]$} \\
\hline Discrete wavelet transform (DWT) & {$[11,16,44,47,48]$} \\
\hline Scale-invariant feature transform (SIFT) or speeded up robust & {$[14,17,18,25,35,36,61,67,74]$} \\
features (SURF) & {$[27]$} \\
\hline Compressed sensing & {$[38]$} \\
\hline Features by optical character recognition (OCR) & {$[8,9,13,17,20,23,30,32,36,38,39,43,48,59,68]$} \\
\hline Features from selected ROI &
\end{tabular}

Among high-performance methods for banknote feature extraction, there are wavelet transform-based methods, with a high computational burden being their drawback $[11,16,44,47,48]$, and methods using the scale-invariant feature transform (SIFT) or speeded up robust features (SURF) algorithm, known to be robust to scale and rotation changes $[14,17,18,25,35,36,61,67,74]$, which have hence been used as methods of feature extraction for banknote recognition. The method based on compressed sensing is known to be useful for data dimension reduction [27]. Features can be extracted using information based on optical character recognition (OCR) as well [38]. Lastly, many methods use selected ROIs, instead of the entire banknote region, as feature extraction regions $[8,9,13,17,20,23,30,32,36,38,39,43,48,59,68]$.

\subsection{Classification and Verification}

The neural network (NN)-based method [15] shown in Figure 8 is the representative method for input banknote classification using the features extracted in the feature extraction step described in Section 2.3.

As shown in Table 4, NN-based methods for classifying input banknotes use various neural networks based on learning vector quantization (LVQ), ensemble networks (ENN) using negative correlation, and probabilistic neural networks (PNN) $[15,16,20-22,24,26,29-34,38,45-47,49,53,54,56-58$, $62,63,66,69,72,73]$.

Among other classification methods listed in Table 4, there are simple methods of comparing distances using the Euclidean distance-based classifier [36,37,41,42,48,51] or the Mahalanobis distance-based classifier [23], and complicated methods using sophisticated pattern recognition-based classifiers, such as support vector machines (SVM) $[8,11,39,43,67,71]$ or hidden Markov models (HMM) $[13,65,71]$. Furthermore, there are methods using the clustering-based K-means classifier [8,9] and denomination classification methods using K-NN ( $k$-nearest neighbors) $[55,64]$. 


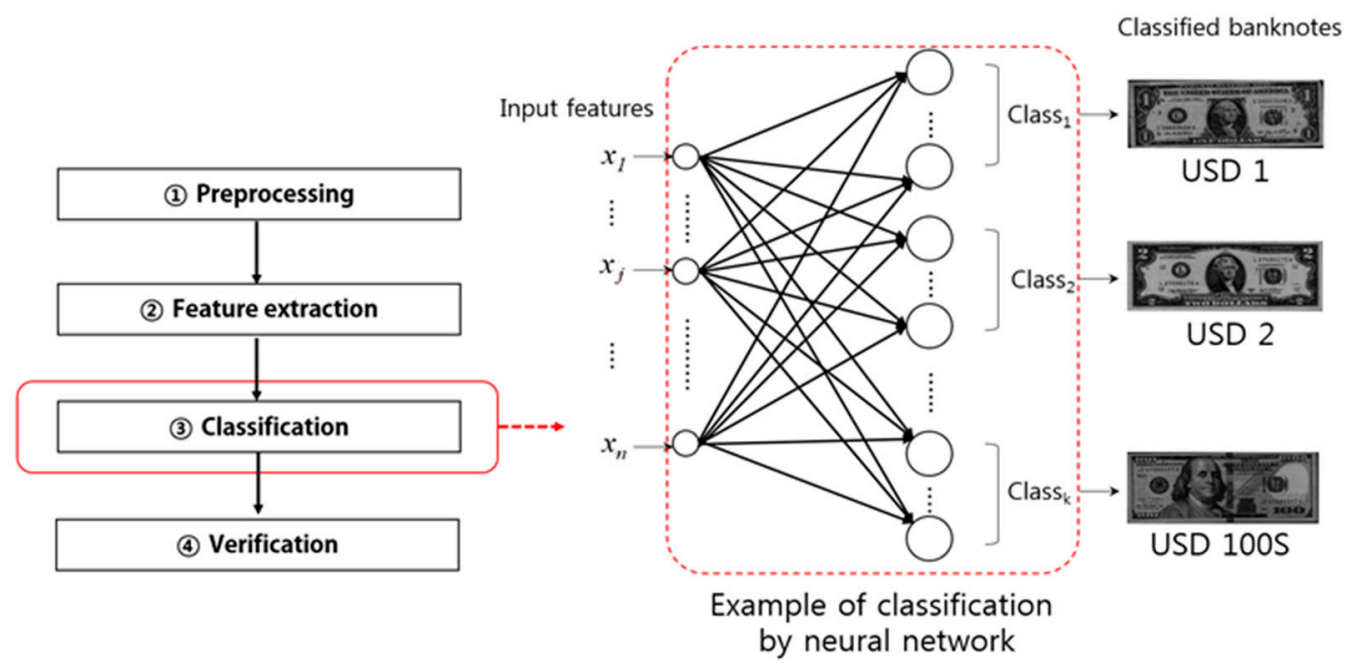

Figure 8. Classification example in the banknote recognition process flow.

Table 4. Studies on classification and verification in the banknote recognition process flow.

\begin{tabular}{|c|c|c|}
\hline & Methods & References \\
\hline \multirow{8}{*}{ Classification } & Euclidean distance-based classifier & {$[36,37,41,42,48,51]$} \\
\hline & Mahalanobis distance-based classifier & [23] \\
\hline & NN (LVQ network, ENN and PNN, etc.) & $\begin{array}{c}{[15,16,20-22,24,26,29-34,38,45-47,} \\
49,53,54,56-58,62,63,66,69,72,73]\end{array}$ \\
\hline & SVM & {$[8,11,39,43,67,71]$} \\
\hline & HMM & {$[13,65,71]$} \\
\hline & K-means algorithm & {$[8,9]$} \\
\hline & K-NN method & {$[55,64]$} \\
\hline & $\begin{array}{l}\text { Preclassification (based on banknote side, direction, } \\
\text { size, or a Gaussian mixture model (GMM)) }\end{array}$ & {$[8,10,32,75]$} \\
\hline Verification & $\begin{array}{l}\text { Verification (based on the validity of matching } \\
\text { distance or banknote size) }\end{array}$ & {$[9,54]$} \\
\hline
\end{tabular}

There are also methods for classifying denominations in which preclassification, based on the banknote input side, direction, size, or a Gaussian mixture model (GMM), is performed before proceeding with denomination recognition on the preclassified banknote with a reduced number of classes for matching $[8,10,32,75]$. This approach can greatly enhance classification accuracy and rapidity because it reduces the number of classes at the preclassification step rather than performing the denomination and side/direction check on all input banknotes.

There are also methods in which the denomination classification errors are reduced by performing verification of the classified banknotes [9,54]. Figure 9 illustrates an example of the verification process in which fake banknote recognition errors and denomination classification errors in the results of classification performed using the Euclidean distance or K-means classifier are removed using threshold 1 based on the distance from the first matched candidate class (located at the shortest distance) and threshold 2 based on the matching distance between the first candidate class (located at the shortest distance) and the second candidate class (located at the second-shortest distance). 


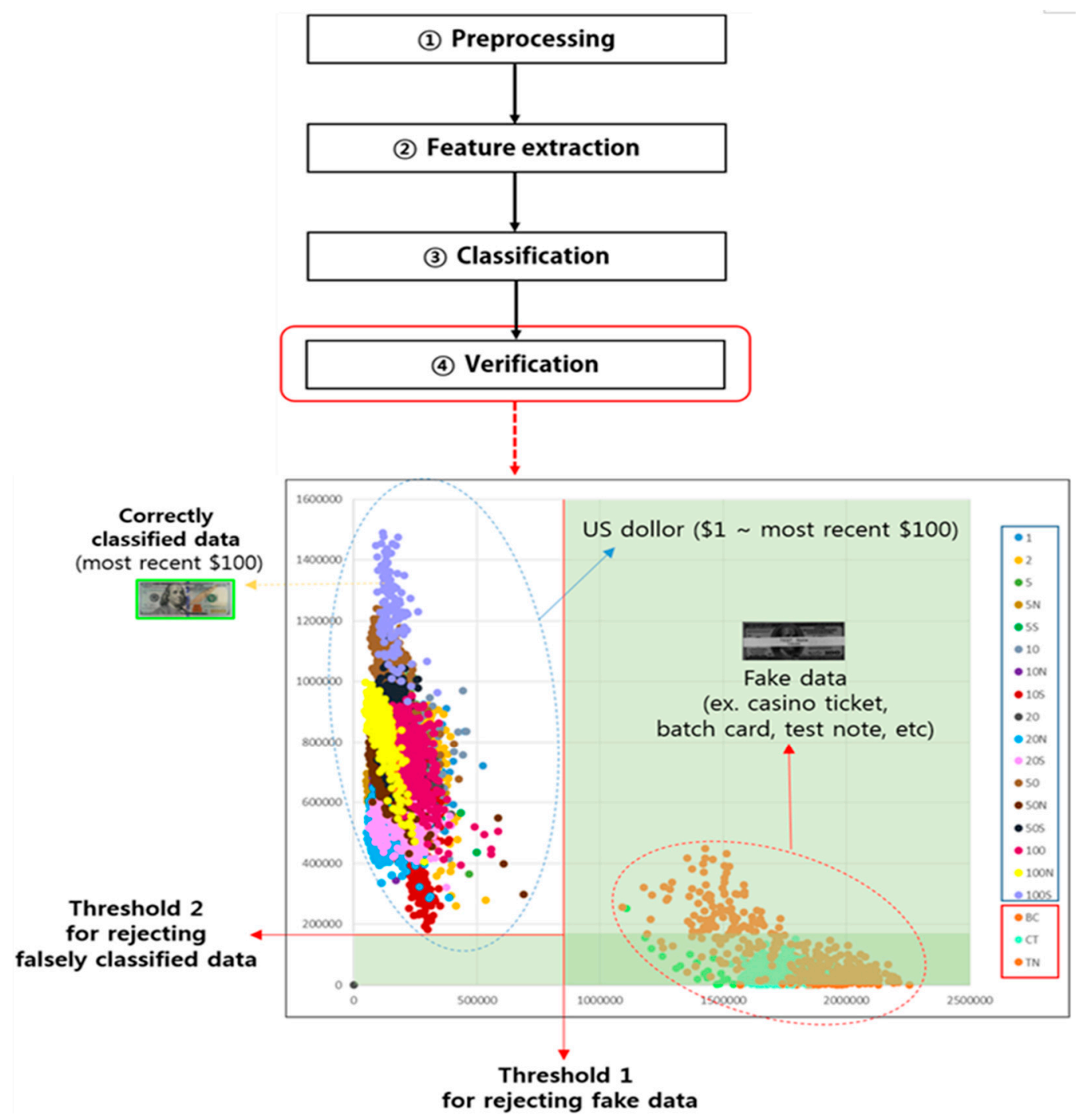

Figure 9. Verification example in the banknote recognition process flow.

Counterfeit banknote recognition errors can be removed as follows: a counterfeit note, such as a casino ticket, batch card, or test note, may be judged a genuine banknote as the first candidate class in the denomination classification step, but because the distance from the first candidate class is shown to be larger compared to that of a genuine banknote, exhibiting a distance going beyond threshold 1 when matched, it is thus rejected as a fake banknote. This is illustrated in Figure 9.

Denomination recognition errors can be reduced as follows: if the difference in the distance between a banknote matched as the first candidate class in denomination classification and the second candidate class is smaller than threshold 2, as shown in Figure 9, the result of the denomination classification for the matched banknote is judged to be unreliable and the matched result is rejected.

\subsection{Analyses and Discussion of Banknote Recognition}

Image-based banknote recognition generally uses color images obtained in the visible light spectrum $[17,18,23,32,38-40,42,45,49,55,60,61,63,68]$ and undergoes general image recognition processes, such as preprocessing, feature extraction, classification, and verification. From the existing body of literature dealing with banknote recognition, important studies were selected and presented in Table 5. Selection criteria were the processing time of the digital signal processor (DSP) environment actually used by the banknote counter, $\geq 95 \%$ recognition rate based on a data size of 
$\geq 10,000$ notes, and significant results yielded in various class environments, such as multi-currency simultaneous recognition.

Table 5. Feature and advantage analyses of existing banknote recognition methods (DSP processing, high-capacity DB, multi-currency simultaneous recognition).

\begin{tabular}{|c|c|}
\hline References & Features and Advantages \\
\hline [8] & $\begin{array}{l}\text { Banknote counter DSP processing (processing time: } 15.6 \mathrm{~ms}) \text {, preclassification of the } \\
\text { banknote input side (SVM), number of experimental data points }(61,240 \text { notes), } \\
\text { accuracy (USD: } 99.886 \%)\end{array}$ \\
\hline [73] & $\begin{array}{l}\text { Banknote counter DSP processing (banknote counting machine by Glory Corp.), GA-based } \\
\text { selection of optimal mask and use of a NN, number of experimental data points } \\
(100,000 \text { notes), accuracy (USD and JPY: } \geq 97 \%)\end{array}$ \\
\hline [9] & $\begin{array}{l}\text { Banknote counter DSP processing, feature region selection using a similarity map, number } \\
\text { of experimental data points ( } 99,236 \text { USD notes), accuracy (USD: } 99.998 \%)\end{array}$ \\
\hline [10] & $\begin{array}{l}\text { Simultaneous recognition of } 5 \text { national currencies (USD, EUR, KRW, CNY, RUB), ROI } \\
\text { selection after using a similarity map, number of experimental data points }(84,800 \text { of } 5 \\
\text { kinds of banknote), accuracy }(100 \%)\end{array}$ \\
\hline [16] & $\begin{array}{l}\text { Quaternion WT-based data extraction of the magnitude, horizontal, vertical, and diagonal } \\
\text { data of banknote images and coefficient feature extraction using the generalized Gaussian } \\
\text { density function, number of experimental data points (15,000 USD, CNY, EUR notes each), } \\
\text { accuracy ( } \geq 99 \% \text { on average) }\end{array}$ \\
\hline [65] & $\begin{array}{l}\text { Simultaneous recognition of } 23 \text { national currencies including USD, EUR, INR, and CNY, } \\
\text { banknote texture feature modeling using size data and a HMM, number of experimental } \\
\text { data points ( } 150 \text { per denomination), recognition rate }(98 \%)\end{array}$ \\
\hline [67] & $\begin{array}{l}\text { ATM DSP processing (processing time: } 54 \mathrm{~ms} \text { ), simultaneous recognition of USD and EUR } \\
\text { using the dense SIFT feature extraction method, accuracy }(\geq 99.8 \%)\end{array}$ \\
\hline [19] & $\begin{array}{l}\text { Real-time embedded system processing (processing time: } 16 \mathrm{~m} \text { ), valid feature region } \\
\text { selection using the difference map, generalized learning vector quantization (GLVQ) } \\
\text { classification, number of experimental data points (65700 USD notes), accuracy (99\%) }\end{array}$ \\
\hline [69] & $\begin{array}{l}\text { GA-based selection of optimal mask, NN-based DSP simultaneous recognition of four } \\
\text { national currencies (JPY, ITL, ESP, FRF) using a banknote counter, number of experimental } \\
\text { data points ( } 20,000 \text { notes), accuracy }(97 \%)\end{array}$ \\
\hline [74] & $\begin{array}{l}\text { Multi-currency simultaneous recognition (INR, CNY, EUR, etc.) using a mobile camera } \\
\text { and server communication system with a feature enabling overlapping multi-currency } \\
\text { simultaneous recognition, recognition rate }(95 \%)\end{array}$ \\
\hline
\end{tabular}

In one study [8], in which an experiment was performed on over 60,000 USD denomination bills in a real banknote counter DSP environment, counting performance of $15.6 \mathrm{~ms}$ per note with a recognition rate of $99.886 \%$ was demonstrated. In the method used in this study, the input banknotes first undergo classification by input side and direction, followed by denomination classification. The salient feature of this method is progressive processing depending on the number of classes to be classified, thus optimizing the processing efficiency. In another study [73] conducted in a real banknote counter DSP environment, an error-free recognition rate of over $97 \%$ was achieved on 100,000 USD and JPY denomination bills by adopting the method of selecting a GA-based optimal mask and applying it to a NN. This method was also adopted in a study [69] in which a $97 \%$ recognition rate was achieved in simultaneous denomination recognition of four national currencies. The methods used in these studies may well be recommended for banknote counters. The method of another study [9] achieved superior results compared to the method used in one of the above-mentioned studies [8] in terms of processing speed and use of memory capacity, also using the method of processing in a real DSP equipment environment, yielding a classification accuracy of $99.998 \%$ on over 90,000 USD denominations. Its particular significance lies in the fact that it extracts an ROI of a 
banknote automatically without manual selection using a similarity map. Another study [10] presented a method for simultaneously recognizing five national currencies (USD, EUR, KRW, CNY, and RUB), demonstrating $100 \%$ accuracy in recognizing 84,800 experimental banknotes without error. Study [16] presented a method using frequency characteristics regarding the directionality of a banknote based on the quaternion WT and confirmed its performance ( $\geq 99 \%$ on average) on 15,000 notes each of USD, EUR, and CNY notes each. Study [65] presented a method of simultaneously recognizing 23 different national currencies, including USD, EUR, INR, and CNY, using the note's size information and a HMM to model its texture characteristics, and demonstrated a classification accuracy of $98 \%$ on 150 notes per denomination.

Study [67] presented a method for an actual banknote ATM DSP environment. With a per-note processing time of $54 \mathrm{~ms}$, it performed simultaneous recognition of USD and EUR and demonstrated a classification accuracy of higher than $99.8 \%$. This method uses the dense SIFT algorithm for feature extraction and is significant as an approach to improving the robustness of the processing rate of the SIFT algorithm against scale change. Study [19] presents a real-time processing method in an embedded system capable of a processing speed of $16 \mathrm{~ms}$ per note using the ROI showing the largest inter-class difference on a difference map and GLVQ-based classification with an accuracy of $99 \%$ on 65,700 USD bills. In the method presented in Study [69], a GA-based optimal mask is selected and applied to a NN, as in Study [73] mentioned above. It demonstrated a multi-currency simultaneous classification accuracy of $97 \%$ on 20,000 JPY, ITL, ESP, and FRF notes using a real banknote counter. Study [74] presented a multi-currency simultaneous recognition method combining a mobile camera and server communication system. It performs complicated recognition operations using a high-performance server computer, thus reducing processing time and enhancing performance. It showed a multi-currency simultaneous recognition accuracy of $95 \%$ on several national currencies, including INR, CNY and EUR. The following issues should be dealt with and solved in the studies of banknote recognition:

- The banknote recognition function of a banknote counter should ensure not only a stable recognition rate, but also real-time processing speed because it continuously handles real money.

- $\quad$ The per-note processing time should be constant because time discrepancy in processing individual notes leads to non-normal storage of continuous high-speed banknote data input, triggering a system crash.

- With the increasing demand for simultaneous multi-currency recognition, stable recognition and a rapid processing speed for an increased number of classes are required, unlike the initially used manual selection-based single-currency recognition methods.

- While there is a considerable body of research presenting numerous banknote recognition methods using feature extraction and classifiers, no study has yet been conducted on the convolutional neural network (CNN)-based banknote recognition, which has recently been attracting attention. This may be ascribed to the difficulty associated with loading a high-performance graphics card capable of the parallel processing essential for high-speed CNN processing onto a banknote counter. Therefore, this method may be applied to server-based high-capacity counting systems in the future.

\section{Counterfeit Banknote Detection}

\subsection{Counterfeit Banknote Detection Method}

\subsubsection{Analyses of Anti-Counterfeiting Features inside a Banknote}

As presented in Figure 5, banknote recognition is followed by counterfeit banknote detection. Most banknotes contain various anti-counterfeiting features. Figure 10 shows images of visible light reflection and ultraviolet fluorescence on a genuine USD 100 bill. Examples of anti-counterfeiting features are color, size, and security threads [76]. 


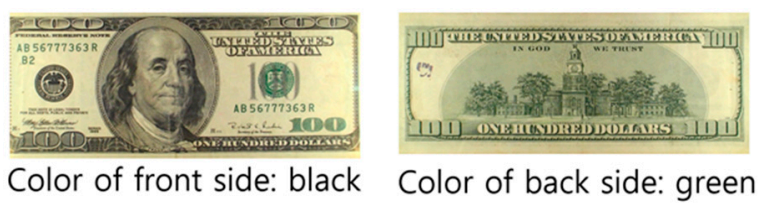

Size of banknote: 156 × $66 \mathrm{~mm}$

(a)

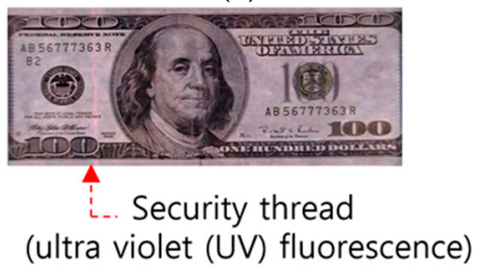

(b)

Figure 10. Visible light reflection image and ultraviolet fluorescence factor on a USD 100 bill: (a) The visible light reflection image of the recent USD \$100; (b) Anti-counterfeiting feature.

Figure 11 highlights the anti-counterfeiting features of a genuine USD 100 bill: the magnetic factor (obverse), two anti-counterfeiting lines responding to IR reflection, and intaglio and engraving technologies (reverse). As illustrated in Figure 11a,b, the magnetic factor and NIR factor contained in a genuine banknote, which are not visible under visible light, are perceived by a magnetic sensor and NIR sensor, respectively. Therefore, counterfeit banknotes without such magnetic and NIR factors can be easily detected by the aforementioned sensors. Figure 11c illustrates the printing technologies used in a genuine USD banknote: the dark-colored parts undergo intaglio printing and the mark or serial number undergo engraving printing. If a counterfeiter applies intaglio or engraving printing to the entire banknote, it can be detected as a counterfeit banknote due to a printing state different from a genuine banknote [76].

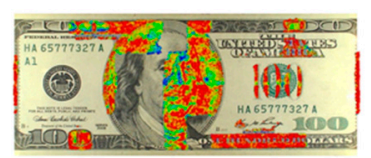

(a)

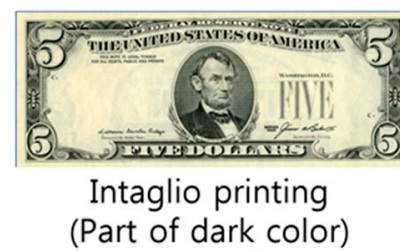

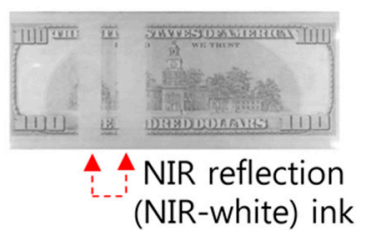

(b)

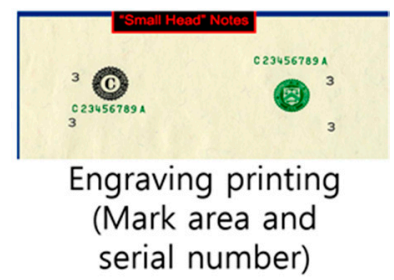

(c)

Figure 11. USD anti-counterfeiting features (magnetic factor, IR factor, and printing technology): (a) Magnetic factor for counterfeit prevention; (b) NIR factor for counterfeit prevention; (c) Printing scheme for a genuine banknote USD.

Figure 12 shows other anti-counterfeiting features on the obverse and reverse sides of a genuine USD 100 bill: a security thread, anti-copier line structure (fine line printing), a watermark, safety fibers, optically variable ink, microlettering (microprinting), and serial numbers. The optically variable ink appears to change color depending on the viewing angle. Microlettering (microprinting) refers to microfine printed letters of specific words, such as "USA 100" and "THE UNITED STATES OF 
AMERICA" in the corresponding parts (Figure 12a). These anti-counterfeiting features are used in the detection of counterfeit banknotes [76-79].

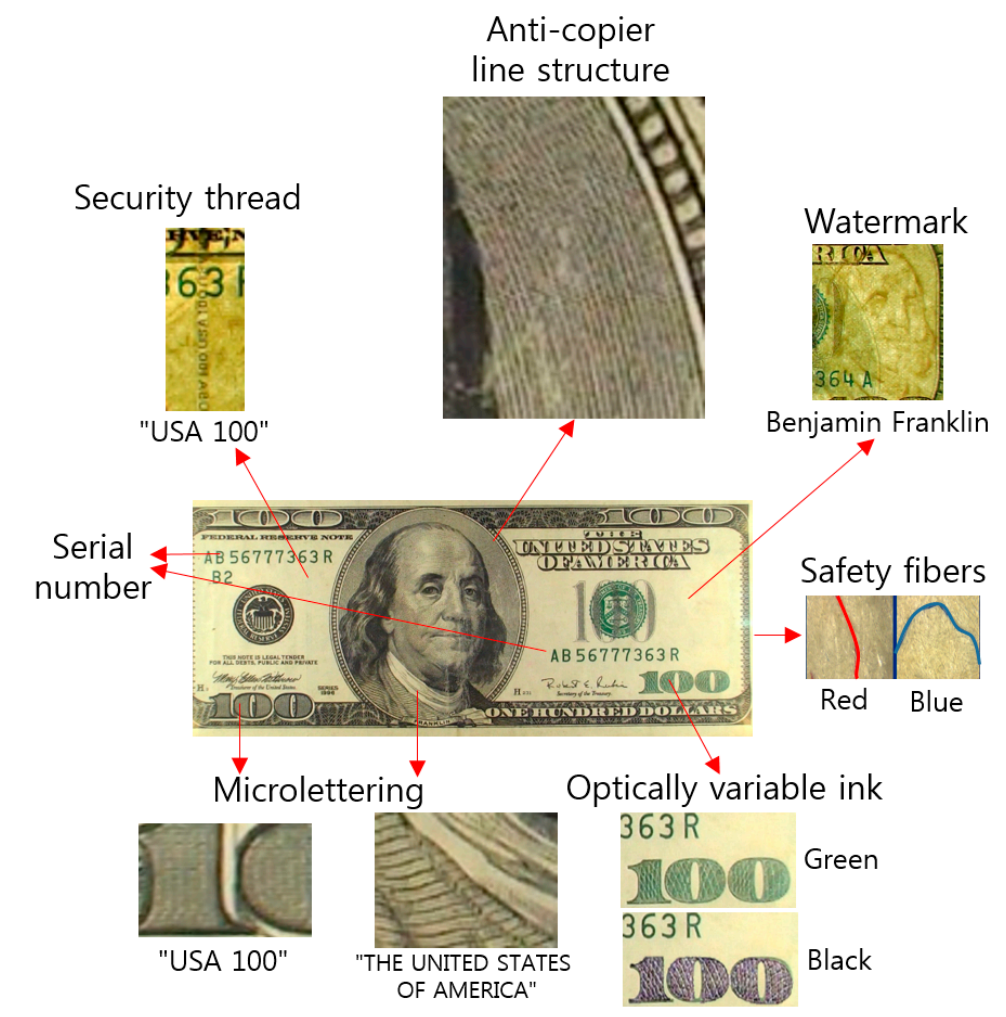

(a)

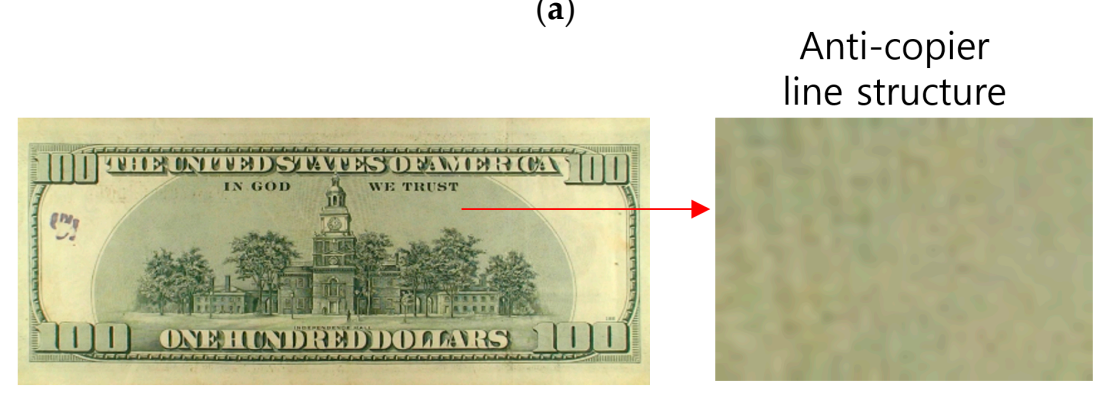

(b)

Figure 12. Analysis of anti-counterfeiting features inside a USD 100 bill: (a) Front side; (b) Back side.

Security features for detecting counterfeit banknotes can be called machine readable security features because they can measured by counterfeit detection machines [80]. In previous research [81], various techniques for printing the security features on genuine banknotes have been reported. These features are different for different denominations, and the security features of EUR are reported in [82].

\subsubsection{Counterfeit Banknote Detection}

As presented in Table 6, there are a variety of methods for identifying anti-counterfeiting features by extracting features related to brightness information [83,84], fluorescence characteristics [85-92], fidelity of the serial number and printing [93,94], and security threads [95]. Simple methods using only wavelengths of the visible light spectrum have limitations in accurately identifying anti-counterfeiting features. Sensors with various spectral ranges to sense UV [85,86,96,97] and IR [75,82,97-101] wavelengths, X-ray, [88] etc. are required. 
Table 6. Methods for identifying anti-counterfeiting features.

\begin{tabular}{|c|c|c|}
\hline Feature & Method & References \\
\hline Brightness information & $\begin{array}{l}\text { Y histogram of YIQ color space or } \\
\text { luminance histogram }\end{array}$ & {$[83,84]$} \\
\hline \multirow{3}{*}{ Fluorescence characteristics } & UV pattern & [85-87] \\
\hline & X-Ray fluorescence & [88-91] \\
\hline & Intrinsic fluorescence lifetime & [92] \\
\hline \multirow{2}{*}{$\begin{array}{c}\text { Fidelity of serial } \\
\text { number and printing }\end{array}$} & $\begin{array}{l}\text { Binarization, edge detection, and radial } \\
\text { based function (RBF) NNs }\end{array}$ & [93] \\
\hline & Printing accuracy by tie point detection & [94] \\
\hline Security thread & $\begin{array}{l}\text { Electromagnetic detection based on the } \\
\text { pulsed eddy current technique }\end{array}$ & [95] \\
\hline \multirow{3}{*}{ Infrared (IR) features } & $\begin{array}{l}\text { The middle IR spectrum of several } \\
\text { areas in the banknotes }\end{array}$ & [96] \\
\hline & Near IR features & {$[75,82,97-100]$} \\
\hline & $\begin{array}{l}\text { Commercial system using multiple sensors } \\
\text { including IR ray sensor }\end{array}$ & [101] \\
\hline
\end{tabular}

Most of the counterfeit banknote detection methods presented in previous studies corresponding to step (3) in Figure 13 (left), are carried out based on denomination and banknote input information (input side, deflection, inclination, etc.) after the banknote recognition step. As mentioned above, the process flow of counterfeit banknote detection bifurcates into the use and non-use of the serial number (Figure 13 case 1 and case 2, respectively).

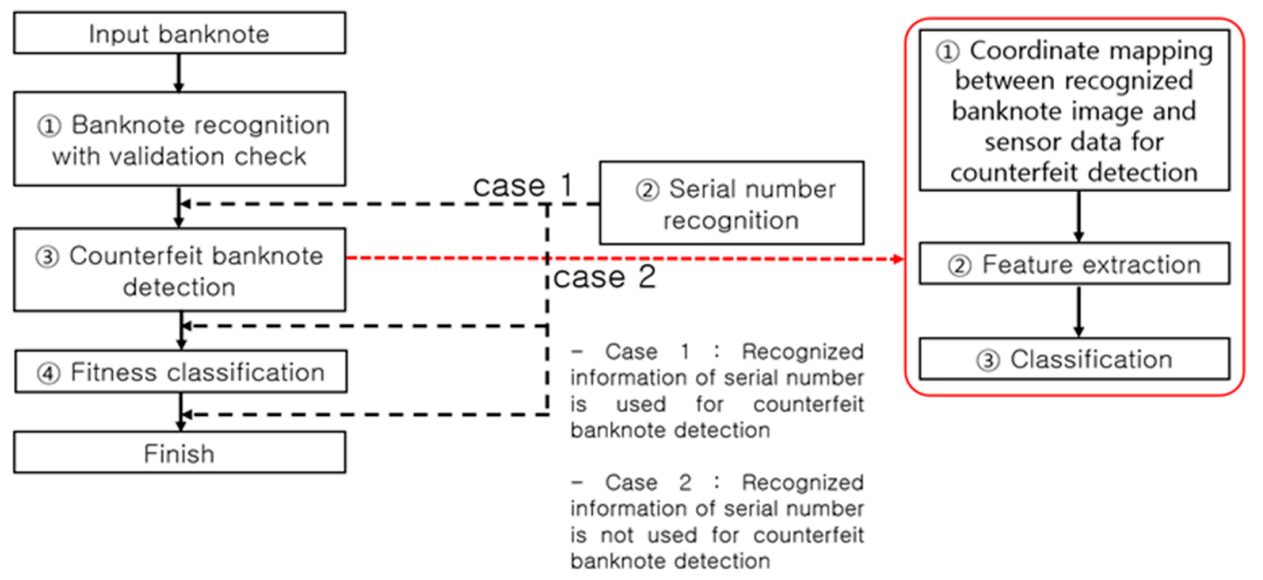

Figure 13. Counterfeit banknote detection process flow.

In Figure 13, (3) counterfeit banknote detection in the overall process flow (left) follows the subprocess steps of (1) coordinate mapping between the recognized banknote image and sensor data for counterfeit detection, (2) feature extraction in which ROIs are selected from the recognized banknote image for anti-counterfeit feature extraction and sensor data are extracted for counterfeit detection based on the related coordinate information, and (3) classification through which counterfeit banknotes identified using the detection features are thus extracted.

As was the case with banknote recognition, anti-counterfeiting features for counterfeit banknote detection vary for individual denominations of the national currency concerned, and their efficiencies may also vary by denomination. Table 7 lists studies that have been conducted on counterfeit banknote detection by national currency. In this table, "N/I" means the case that the detail information is not shown in the paper. "N/A" represents the case that the database is not available for research purpose. 
The largest number of studies on counterfeit banknote detection focus on the Indian rupee, followed by the Euro and US dollar. In Table 7, the largest numbers of images are included in the database of [98]. All the databases are not available because the available counterfeit banknote can be illegally used.

Table 7. Studies on counterfeit banknote detection by currency (Ref.: References, N/I: Not Informed, N/A: Not Available).

\begin{tabular}{|c|c|c|c|c|c|}
\hline \multirow{2}{*}{ National Currency } & \multirow{2}{*}{ References } & \multicolumn{3}{|c|}{ Databases } & \multirow{2}{*}{$\begin{array}{c}\text { Availability o } \\
\text { Database }\end{array}$} \\
\hline & & Ref. & \#Images & \#Denomination Kind & \\
\hline \multirow{2}{*}{ India (INR) } & \multirow{2}{*}[84,87,99,102-115]{} & [87] & 1000 & 2 & $\mathrm{~N} / \mathrm{A}$ \\
\hline & & [113] & 288 & 3 & $\mathrm{~N} / \mathrm{A}$ \\
\hline \multirow{2}{*}{ Euro (EUR) } & \multirow{2}{*}[88,94,96,98]{} & [96] & 18 & 2 & $\mathrm{~N} / \mathrm{A}$ \\
\hline & & [98] & 2750 & 7 & $\mathrm{~N} / \mathrm{A}$ \\
\hline \multirow{2}{*}{ United States (USD) } & \multirow{2}{*}[88,91,92]{} & [91] & 120 & 2 & $\mathrm{~N} / \mathrm{A}$ \\
\hline & & [92] & 10 & 5 & $\mathrm{~N} / \mathrm{A}$ \\
\hline Kuwait (KWD) & [116] & & 4 & 2 & $\mathrm{~N} / \mathrm{A}$ \\
\hline Nepal (NPR) & [117] & & 240 & 1 & $\mathrm{~N} / \mathrm{A}$ \\
\hline Switzerland (CHF) & {$[118]$} & & 82 & 2 & $\mathrm{~N} / \mathrm{A}$ \\
\hline \multirow{2}{*}{ Taiwan (TWD) } & \multirow{2}{*}[83,119]{} & [83] & 99 & $\mathrm{~N} / \mathrm{I}$ & $\mathrm{N} / \mathrm{A}$ \\
\hline & & [119] & 200 & $\mathrm{~N} / \mathrm{I}$ & $\mathrm{N} / \mathrm{A}$ \\
\hline \multirow{2}{*}{ South Korea (KRW) } & \multirow{2}{*}[85,86]{} & [85] & 360 & 3 & $\mathrm{~N} / \mathrm{A}$ \\
\hline & & [86] & $\mathrm{N} / \mathrm{I}$ & 9 & $\mathrm{~N} / \mathrm{A}$ \\
\hline United Kingdom (GBP) & [95] & & 3 & 2 & $\mathrm{~N} / \mathrm{A}$ \\
\hline China (CNY) & [86] & & $\mathrm{N} / \mathrm{I}$ & 1 & $\mathrm{~N} / \mathrm{A}$ \\
\hline Malaysia (MYR) & [86] & & $\mathrm{N} / \mathrm{I}$ & 1 & $\mathrm{~N} / \mathrm{A}$ \\
\hline
\end{tabular}

\subsection{Coordinate Mapping between Recognized Banknote Image and Sensor Data for Counterfeit Detection}

Methods for counterfeit banknote detection are usually applied after the banknote recognition step for the validation check of the input banknote by judging the genuineness of each feature based on the input denomination and input information (input side, direction, deflection, inclination, etc.), combining such input data with IR, UV, and MG sensor data related to individual anti-counterfeiting features. Figure 14 illustrates an example of matching a banknote image and sensor signals around the ROIs for anti-counterfeiting features when a note recognized as a genuine banknote is input.

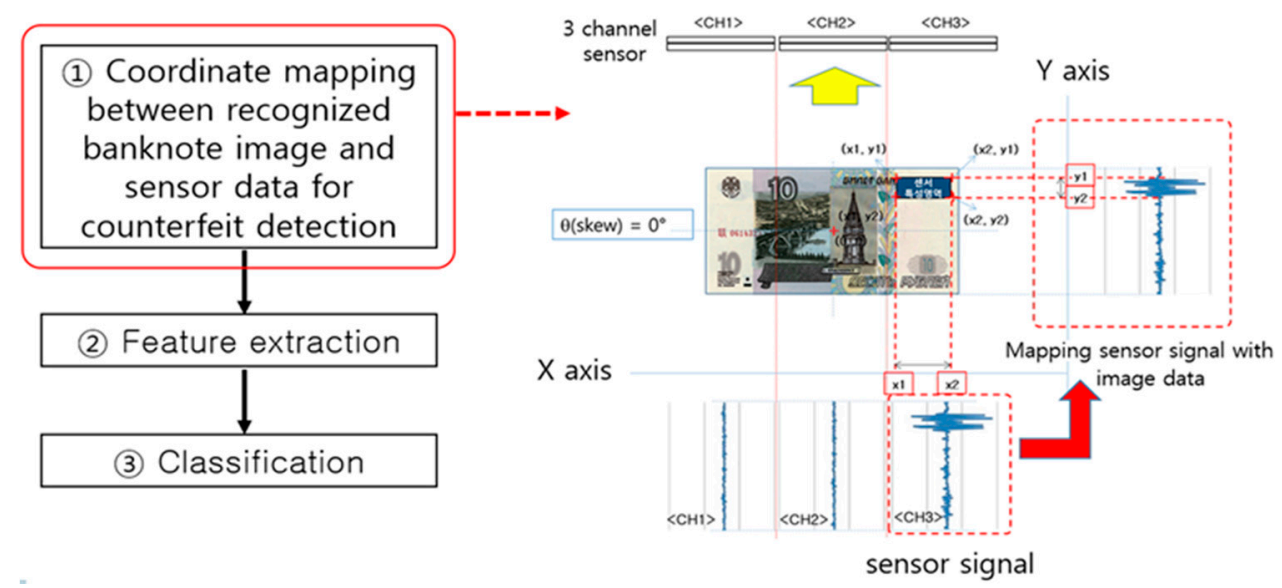

Figure 14. Example of data matching between banknote image and sensor data in the counterfeit banknote detection process flow. 


\subsection{Feature Extraction}

Anti-counterfeiting features can be extracted using the sensor signals matched in predetermined ROIs, as shown in the example of extracting a feature using the UV-scanned signal of the corresponding ROI presented in Figure 15. Likewise, various methods listed in Table 6 are employed for counterfeit detection using light of various spectral ranges besides visible light or MG information.

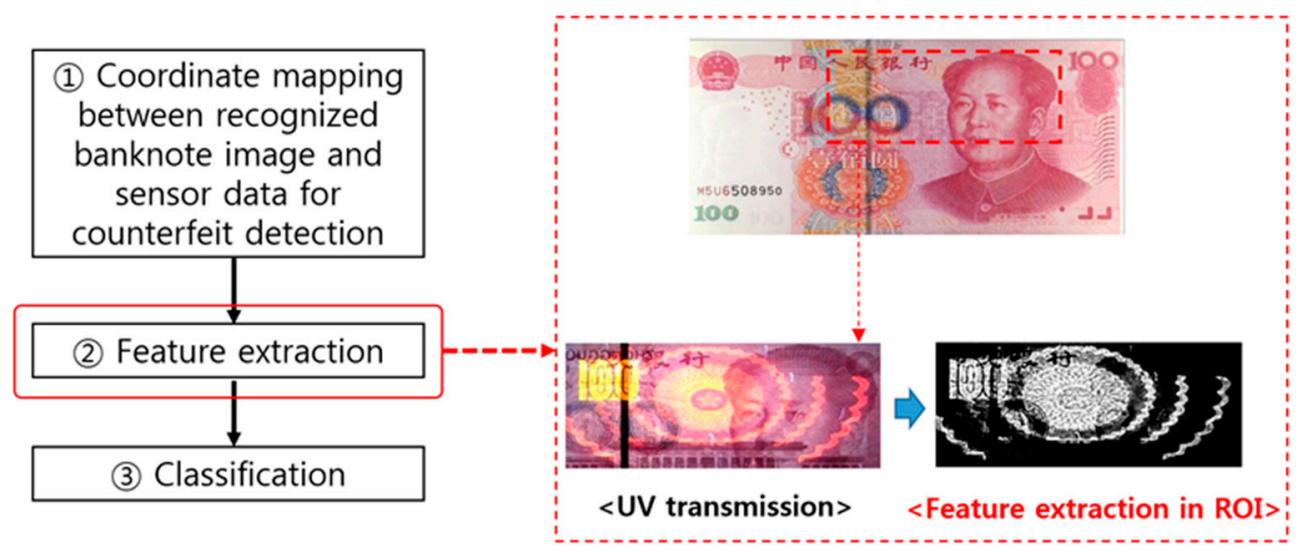

Figure 15. Example of UV anti-counterfeiting feature extraction within an ROI in the counterfeit banknote detection process flow.

Table 8 lists various methods for extracting anti-counterfeiting features, such as intaglio printing, ink properties, artwork, fluorescence, or year of printing-based feature extraction [87,106], bit-plane slicing and canny edge detection [116], watermark-based feature extraction [105,106,108,110,113,114], and luminance histograms and texture features from GLCM [84]. As shown in Table 7, the Indian rupee INR has been most intensively studied with respect to counterfeit detection, frequently by using methods for extracting features related to intaglio printing, ink properties, artwork, fluorescence, year of printing, watermarks, security threads, optically variable ink, identification marks, number panels, microlettering or latent images. With the continuing trend of increasingly sophisticated counterfeit banknotes, studies on more accurate counterfeit banknote detection methods based on multi-features are underway.

Table 8. Methods for feature extraction in the counterfeit banknote detection process flow.

\begin{tabular}{ll}
\hline \multicolumn{1}{c}{ Method } & \multicolumn{1}{c}{ References } \\
\hline Features from intaglio printing, ink properties, artwork, fluorescence, or year of printing & {$[87,106]$} \\
Bit-plane slicing and Canny edge detection & {$[116]$} \\
Watermark segmentation & {$[105,106,108,110,113,114]$} \\
Luminance histograms and texture features from GLCM & {$[84]$} \\
DWT & {$[102]$} \\
Security thread information & {$[87,103-105,110,113,114]$} \\
Optically variable ink information & {$[106,110,113]$} \\
SIFT algorithm & {$[112]$} \\
Mean, standard deviation, skewness, entropy, and correlation in an ROI & {$[117]$} \\
Identification mark or number panels & {$[103-106]$} \\
Micro lettering or latent image & {$[104,106]$} \\
\hline
\end{tabular}

If a banknote is in circulation for a long time, it may be difficult to extract correct features for counterfeit banknote detection due to its surface being soiled by dirt and sebum from users' hands. To solve this problem, noise removal is performed as a general preprocessing step using techniques based on median filtering [87,116], intensity thresholding [97], frame averaging [98], Gaussian low-pass filtering [120], and truncated-inhomogeneity-value with squared-homogeneity-difference [75]. 
Some studies have presented methods to normalize the brightness and improve the contrast of the images [116,117].

\subsection{Classification of Counterfeit Banknote}

Classification, the last step in counterfeit banknote detection, is carried out using the anti-counterfeiting features extracted in the previous step. Methods used for counterfeit classification are similar to those used for classifying banknote recognition. Unlike banknote recognition, the two classes are genuine banknote and counterfeit banknote. Figure 16 illustrates an example of SVM-based counterfeit banknote classification.

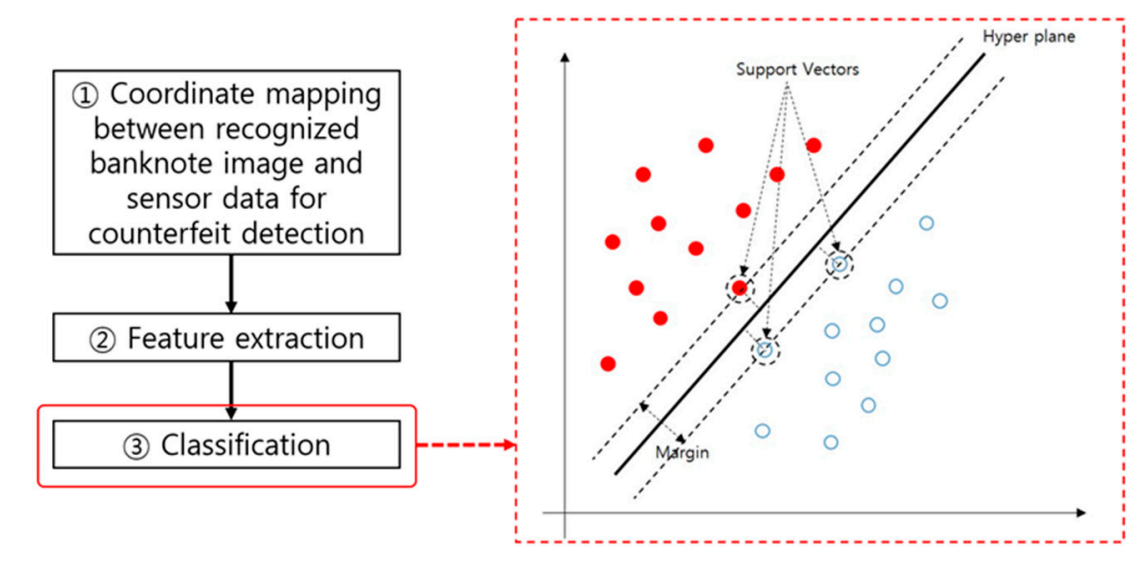

Figure 16. SVM-based counterfeit banknote classification in the counterfeit banknote detection process flow.

As listed in Table 9, counterfeit banknote classification is performed using various algorithms such as template matching [106] or keypoint matching [117], an artificial NN [121], an SVM [84,87,119] or multiple kernel SVM [111].

Table 9. Methods for classification in the counterfeit banknote detection process flow.

\begin{tabular}{cc}
\hline Method & References \\
\hline Template matching or keypoint matching & {$[106,117]$} \\
Artificial NN & {$[121]$} \\
SVM & {$[84,87,119]$} \\
Multiple kernel SVM & {$[111]$} \\
\hline
\end{tabular}

\subsection{Analyses and Discussion of Counterfeit Banknote Detection}

As mentioned above, unlike in the banknote recognition classification process, in which various classes have to be identified concurrently, counterfeit detection needs to classify only two classes, genuine banknotes and counterfeit banknotes, and the classifier may be accordingly considered less complicated.

However, the following two issues should be dealt with and solved in counterfeit banknote detection studies:

- $\quad$ Given the highly sophisticated techniques used for producing counterfeit banknotes, distinguishing them from genuine banknotes poses a great challenge. For counterfeit banknote classification, it is absolutely necessary to perform precise analyses of the characteristics of all anti-counterfeiting features (security features deliberately included in banknotes to deter counterfeiting) contained in the genuine banknotes of the denominations concerned. 
- Counterfeit banknote detection is a perpetual process; if a highly efficient counterfeit detection algorithm is developed, more refined counterfeit banknotes disabling that algorithm appear, which necessitates the development of another algorithm to detect them in a never-ending spear-and-shield fight. For this reason, it is practically impossible to design a 100\% perfect long-lasting counterfeit detection algorithm with a genuine banknote false rejection rate of $0 \%$. As an alternative approach, developing a highly efficient counterfeit detection algorithm that would increase the counterfeit banknote production costs to such an extent that it is not worth making counterfeit banknotes may put an end to this endless combat.

\section{Serial Number Recognition}

\subsection{Overall Procedure of Serial Number Recognition}

The serial number recognition step follows the banknote recognition step. It is carried out by performing image recognition of the ROI for the serial number specific to the denomination concerned using its position information based on the banknote recognition data. As shown in Figure 17, the serial number recognition process also goes through the subprocess steps of image preprocessing, feature extraction, and classification.

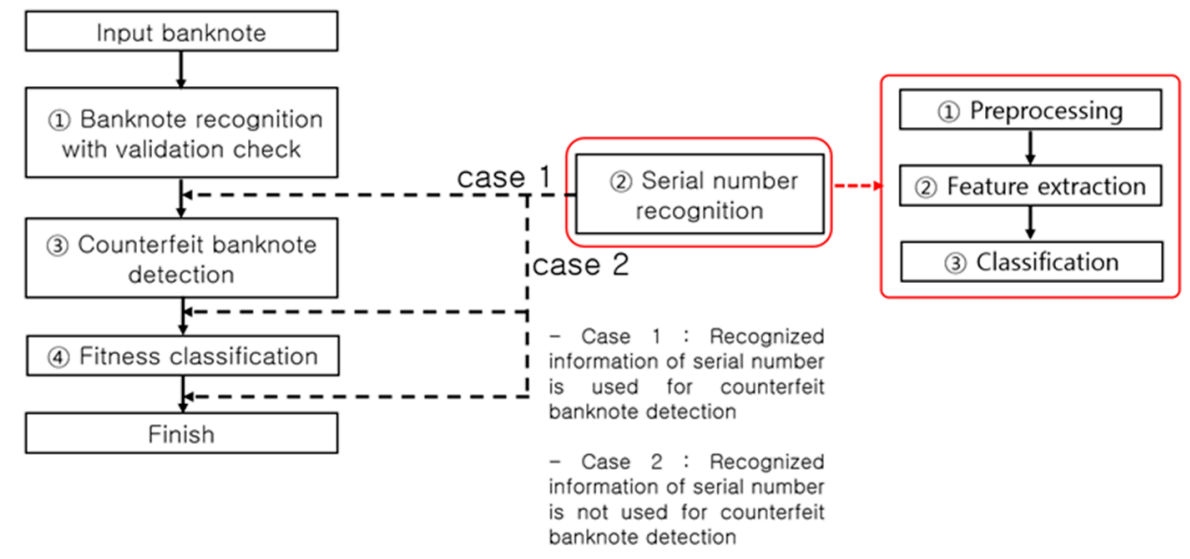

Figure 17. Serial number recognition process flow.

Like banknote recognition and counterfeit banknote detection, serial number recognition may have different degrees of accuracy depending on the currency type. Studies on serial number recognition can be divided into studies on the Chinese and Indian national currencies, as listed in Table 10.

Table 10. Resources on serial number recognition by currency (Ref.: References, N/I: No Information, A: Available, N/A: Not Available).

\begin{tabular}{cccccc}
\hline \multirow{2}{*}{ National Currency } & \multirow{2}{*}{ References } & \multicolumn{3}{c}{ Databases } & \multirow{2}{*}{$\begin{array}{c}\text { Availability of } \\
\text { Database }\end{array}$} \\
\cline { 3 - 5 } & \multirow{3}{*}{ China (CNY) } & Ref. & \#Images & \#Denomination Kind & N/A \\
\cline { 3 - 6 } & {$[93,122-128]$} & {$[122]$} & 40,000 & 2 & N/A \\
\cline { 3 - 6 } & & {$[125]$} & 5000 & N/I & $\mathrm{A}$ \\
\hline India (INR) & {$[129-132]$} & {$[129,130]$} & 25 & 2 & N/A \\
\hline
\end{tabular}

In this table, "N/I" means the case that the detail information is not shown in the paper. " $\mathrm{A}$ " represents the case that the database is available for research purpose whereas "N/A" shows the case that the database is not available. In Table 10, the largest numbers of images are included in the database of [122]. Most databases are not available except for those in [126,127]. 


\subsection{Image Preprocessing}

Following the banknote recognition process, the preprocessing step of serial number recognition generally undergoes noise-removal and binarization processes on the serial number ROI, as illustrated in Figure 18. Segmentation separating the serial number components from the background is performed as preprocessing for feature extraction to distinguish the individual letters/numbers of a serial number.

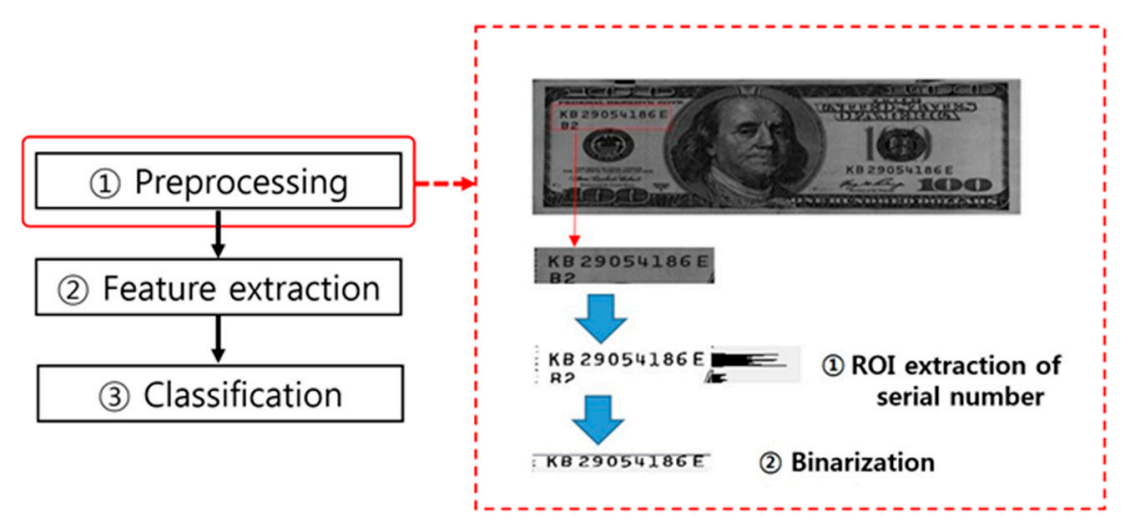

Figure 18. Example of image preprocessing in the serial number recognition process flow.

Table 11 lists the methods used in the preprocessing step of serial number recognition. If a banknote is in circulation for a long time, it may be difficult to distinguish its serial number from the background due to its surface being soiled by dirt and sebum from users' hands. To address this, brightness normalization of the banknote image is performed using various methods such as mean filtering-based noise reduction [122,123], adjustment of brightness, contrast, and gamma [129], and gray-scale normalization [126]. Other measures include size normalization by bilinear interpolation [124] and binarization based on the area-ratio and block contrast [125]. These preprocessing measures render a banknote fit for separating the serial number from the background. Each letter/number of a serial number can then be distinguished from the background with prior information regarding the horizontal and vertical lengths of each letter/number in the serial number and a method to detect the outermost boundary positions of the horizontal and vertical directions of each letter/number [125].

Table 11. Methods for preprocessing in the serial number recognition process flow.

\begin{tabular}{cc}
\hline Methods & References \\
\hline Mean filtering for noise reduction & {$[122,123]$} \\
Adjustment of brightness, contrast, and gamma & {$[129]$} \\
Size normalization by bilinear interpolation & {$[124]$} \\
Binarization based on the area-ratio and block contrast & {$[125]$} \\
Gray-scale normalization & {$[126]$} \\
\hline
\end{tabular}

\subsection{Feature Extraction}

After preprocessing, serial number feature extraction is carried out on each ROI extracted as an individual letter/number, as illustrated in Figure 19, which presents an example of key-point-based feature extraction.

Serial number feature extraction is carried out using the methods presented in Table 12, namely extraction of features from nine local regions and four key-point features from each number/letter region [122] and extraction of gradient direction features [126]. Compared with the aforementioned feature extraction methods for banknote recognition and counterfeit banknote detection, there are 
only a limited number of studies on feature extraction for serial numbers. This may be attributed to the fact that serial number recognition can be classified, once the letter/number region of the serial number is detected, using a gray or binarized image, without going through the feature extraction step requiring a separate processing time because there are only letters/numbers and background in the serial number region.

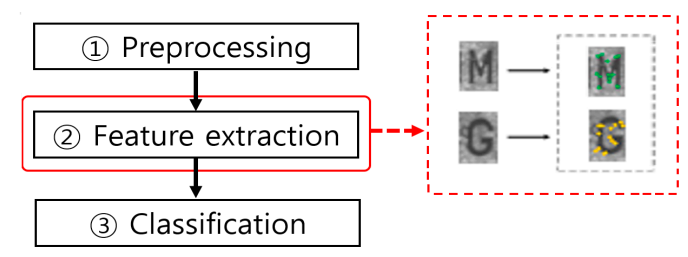

Figure 19. Example of key-point-based feature extraction in the serial number recognition process flow.

Table 12. Methods for feature extraction in the serial number recognition process step.

\begin{tabular}{cc}
\hline Method & References \\
\hline Features from nine local regions and four key-point features & {$[122]$} \\
Gradient direction feature & {$[126]$} \\
\hline
\end{tabular}

\subsection{Classification}

Classification is carried out after determining the classes of the extracted the letters/numbers comprising the serial number based on their characteristics. Figure 20 illustrates an example of NN-based classification of a serial number.

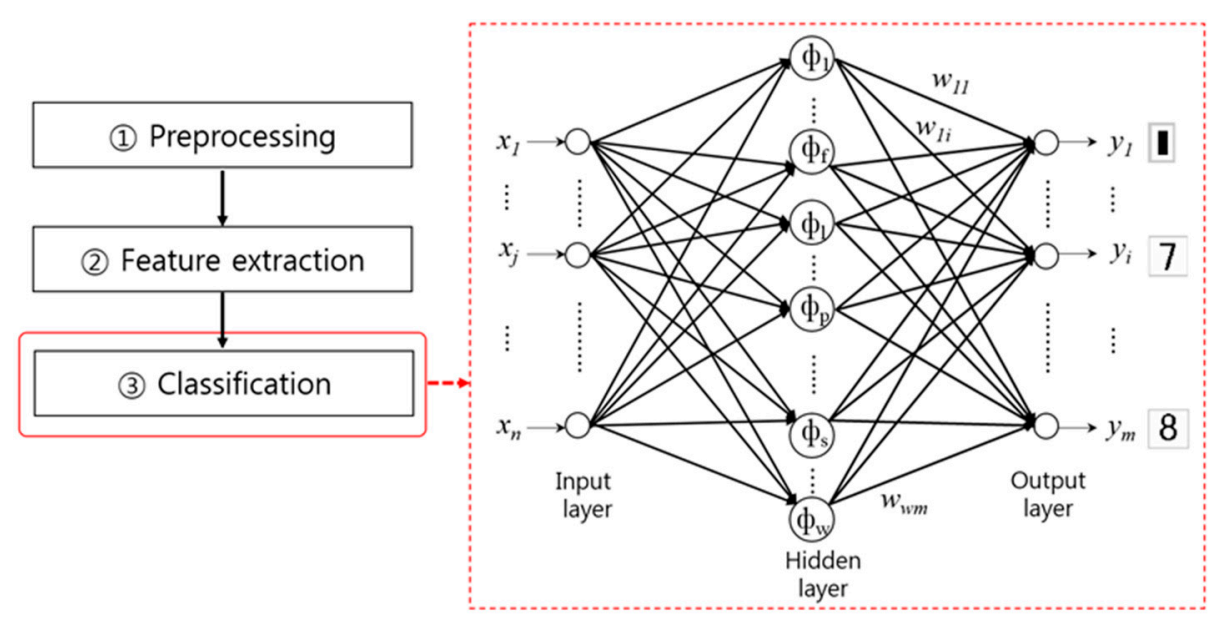

Figure 20. Example of NN-based classification in the serial number recognition process step.

As listed in Table 13, algorithms for classification used in the last step of the serial number recognition process step include the Euclidean distance-based matching method [122], SVMs [123], NNs [124,128], and a cascaded combination of multiple classifiers [126].

Table 13. Methods for classification in the serial number recognition process flow.

\begin{tabular}{cc}
\hline Method & References \\
\hline Euclidean distance-based matching & {$[122]$} \\
SVM & {$[123]$} \\
NN & {$[124,128]$} \\
Cascaded combination of multiple classifiers & {$[126]$} \\
\hline
\end{tabular}




\subsection{Analyses and Discussion of Serial Number Recognition}

The following issues should be considered in banknote serial number recognition studies:

- While serial number recognition is methodologically similar to other in-document number recognition problems, it differs from them in that banknote surfaces get soiled over time due to dirt and sebum from users' hands, making it increasingly difficult to distinguish the serial number from the background surface as a banknote ages. Moreover, banknotes are frequently exposed to risks of damage, such as creases and tears. This makes it necessary to design a strong system capable of serial number recognition on the images of various conditions of banknotes, including those heavily soiled with hand sebum and dirt or tattered with creases and tears.

- In general, a banknote serial number contains the year of printing and information on the issuing bank. Such information can be effectively used for tracing stolen money and detecting counterfeit banknotes once a denomination-wise banknote management system is established.

\section{Fitness Classification}

\subsection{Overall Procedure of Fitness Classification}

Fitness classification of a banknote generally refers to a technique to assess its soiling level using visible light and NIR image information. Unlike the image of a clean banknote, a banknote soiled by users' hand dirt or sebum as the result of long use shows decreased brightness on a visible light or NIR image. A variety of factors influence the physical state of a banknote, such as the aforementioned soiling through dirt and sebum of users' hands, creases, tears, and scribbling. Most of the previous studies on fitness classification use the soiling level as the criterion for judging a banknote fit or unfit for further circulation. As shown in Figure 21, fitness classification is carried out in the order of feature extraction and classification.

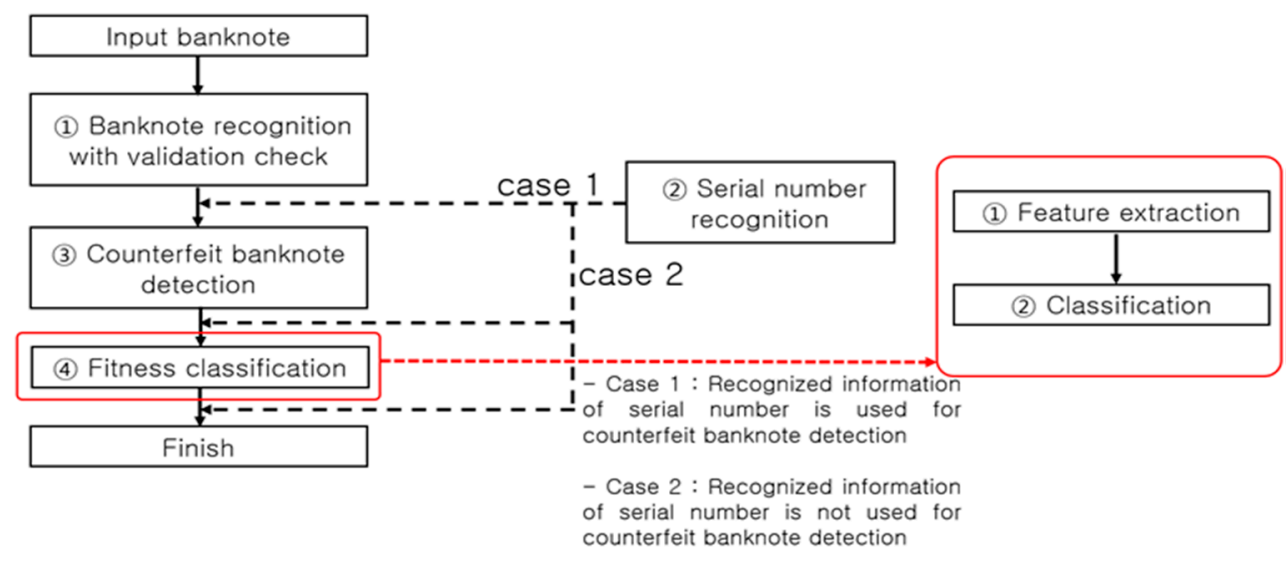

Figure 21. Process flow of fitness classification.

The standards and accuracy of fitness classification vary according to the currency. Table 14 shows that studies have been conducted on fitness classification of EUR, INR, CNY, USD, and KRW. In this table, " $\mathrm{A}$ " represents the case that the database is available for research purpose whereas "N/A" shows the case that the database is not available. In Table 14, the largest numbers of images are included in the database of [137]. Most databases are not available except for that in [138]. 
Table 14. Studies on fitness classification by national currency (Ref.: References, A: Available, N/A: Not Available).

\begin{tabular}{|c|c|c|c|c|c|}
\hline \multirow{2}{*}{ National Currency } & \multirow{2}{*}{ References } & \multicolumn{3}{|c|}{ Databases } & \multirow{2}{*}{$\begin{array}{c}\text { Availability of } \\
\text { Database }\end{array}$} \\
\hline & & Ref. & \#Images & \#Denomination Kind & \\
\hline \multirow{2}{*}{ Euro (EUR) } & \multirow{2}{*}[100,133-136]{} & [100] & 800 & 4 & N/A \\
\hline & & {$[133,136]$} & 9029 & 4 & $\mathrm{~N} / \mathrm{A}$ \\
\hline \multirow{2}{*}{ India (INR) } & \multirow{2}{*}[137,138]{} & {$[137]$} & 19,300 & 5 & $\mathrm{~N} / \mathrm{A}$ \\
\hline & & [138] & 2300 & 6 & $\mathrm{~A}$ \\
\hline China (CNY) & {$[139,140]$} & [140] & 4400 & 1 & $\mathrm{~N} / \mathrm{A}$ \\
\hline United States (USD) & \multicolumn{2}{|l|}{ [138] } & 3856 & 7 & $\mathrm{~A}$ \\
\hline South Korea (KRW) & \multicolumn{2}{|l|}{ [138] } & 3956 & 4 & $\mathrm{~A}$ \\
\hline
\end{tabular}

\subsection{Feature Extraction}

There are various feature extraction methods for fitness classification based on the aforementioned basic assumption that as the soiling level of a banknote increases, its image tends to be less bright, occasionally showing a higher dispersion rate. As shown in the example in Figure 22, a DWT can be used to extract such features for fitness classification.

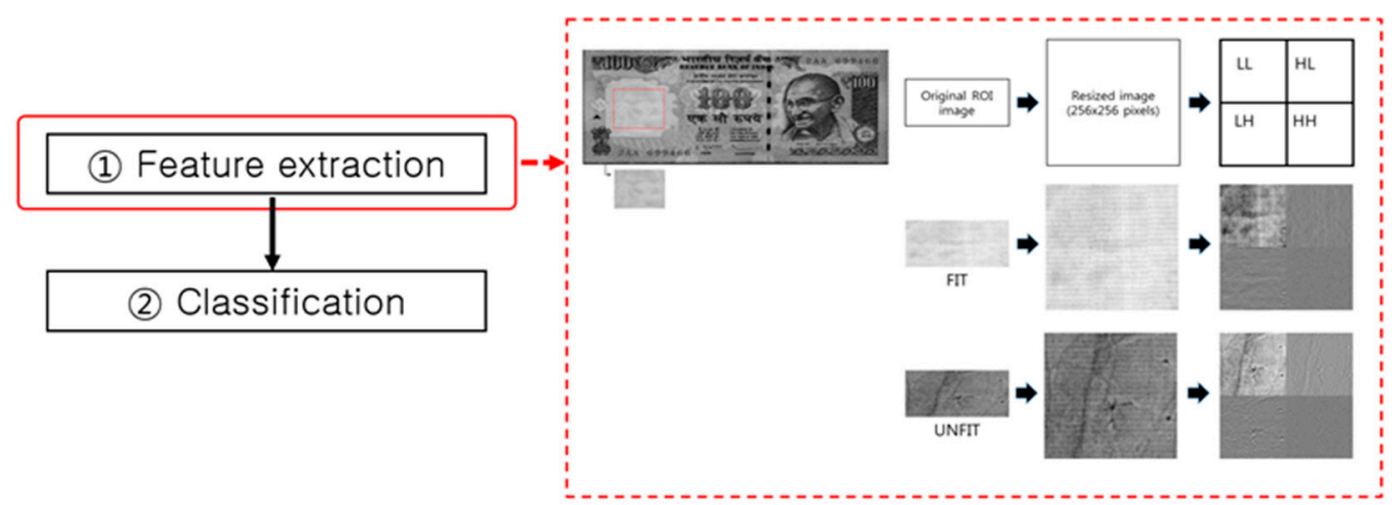

Figure 22. Feature extraction in the fitness classification process flow.

Table 15 lists various methods that have been used for feature extraction for fitness classification, such as gray pixel value [133], color pixel value $[133,135,136]$, pixel values of visible light and NIR images [100,134,138], gray level histogram [139], mean and standard deviation from the ROI by DWT [137], and acoustic features [141,142]. All methods, except for that using acoustic features, use visible light or NIR reflection or transmission images. The study on acoustic features adopted an approach to fitness verification using changes in acoustic features of a banknote, drawing on the fact that a banknote soiled by dirt and sebum from human hands becomes thicker. One of the listed studies presented a method using NIR transmission images instead of reflection images [138].

Table 15. Methods for feature extraction in the fitness classification process flow.

\begin{tabular}{cc}
\hline Method & References \\
\hline Gray pixel value & {$[133]$} \\
Color pixel value & {$[133,135,136]$} \\
Pixel values of visible light and NIR images & {$[100,134,138]$} \\
Gray level histogram & {$[139]$} \\
Mean and standard deviation from ROI by DWT & {$[137]$} \\
Acoustic features of banknotes & {$[141,142]$} \\
\hline
\end{tabular}




\subsection{Fitness Classification}

The final fitness classification can be performed in the classification step using various types of classifier similar to that of the banknote recognition and serial number recognition processes. A method using an SVM-like nonlinear classifier, as shown in Figure 23, was also studied.

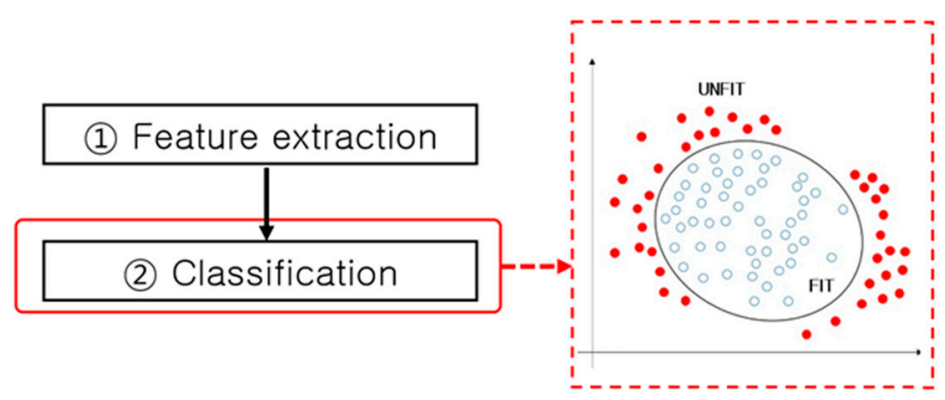

Figure 23. Classification in the fitness classification process flow.

As listed in Table 16, methods used for the classification step of the fitness classification process include the Adaboost classifier [133,136], NNs [100,139], SVMs [137,140], and fuzzy systems [138]. As in the counterfeit detection process, banknotes are classified into two classes: fit and unfit.

Table 16. Methods for classification in the fitness classification process flow.

\begin{tabular}{cc}
\hline Method & References \\
\hline Adaptive boosting (Adaboost) classifier & {$[133,136]$} \\
NN (RBF network or sine basis function) & {$[100,139]$} \\
SVM & {$[137,140]$} \\
Fuzzy system & {$[138]$} \\
\hline
\end{tabular}

\subsection{Analyses and Discussion of Fitness Classification}

Fitness classification of banknotes has been a neglected research area in comparison with banknote recognition and counterfeit banknote classification. However, with increasing penetration of automated self-service machines, such as ATMs, mechanical breakdown caused by unfit banknotes has become a serious maintenance and repair issue. Banknotes with high soiling levels also pose problems to banknote counters because they trigger false recognition and false rejection problems in banknote recognition, counterfeit banknote detection, and serial number recognition. Banks ensure circulation of only fit banknotes by withdrawing unfit banknotes from circulation by means of continuous fitness classification. In this context, fitness classification of banknotes has recently been attracting more attention. The following two issues should be considered in banknote fitness classification studies:

- Most methods for fitness classification classify banknotes into two classes: fit and unfit banknotes. However, such a binary classification has the inherent problem of requiring subjective judgment without any clear-cut quantifiable criteria. Therefore, experts are usually involved to perform visual assessment of the soiling level of banknotes, or densitometers are used to distinguish fit and unfit banknotes depending on the measured values.

- Besides the binary classification of fit and unfit banknotes, it is also important to ensure reproducibility of the assigned fitness level when the same banknote is put into a machine repeatedly.

\section{Conclusions}

Automated machines such as ATMs and banknote counters are indispensable for large-scale banknote circulation and safe transactions. Recent years have also seen extensive research on banknote 
recognition for visually impaired persons $[18,23,42,52,143]$. While many studies have been conducted on banknote recognition methods [143-153] or counterfeit banknote detection methods [97,120], this study provides an overview of the overall banknote recognition systems and describes in detail each of the process steps of banknote recognition, counterfeit banknote detection, serial number recognition, and fitness classification, listing the related studies and describing the methods presented by them. These methods are used to recognize banknote information (denomination, counterfeit detection, serial number, and fitness classification) using images or sensor data and can be applied to automated banknote dispensers and similar self-service terminals. As mentioned above, algorithms related to banknote recognition can show different performance characteristics for different currencies and numbers of target classes. The more similar the patterns among the denominations of a national currency and the higher the number of classes for classification, the lower the performance of the applied algorithm, and a stronger algorithm is required. However, an algorithm with a large number of computational operations cannot be efficiently used for devices requiring rapid processing in an embedded system environment without the aid of a PC, such as a banknote counter. Therefore, developing a banknote recognition algorithm with high recognition accuracy and processing speed is a great challenge for researchers. Besides banknote recognition, coin classification has recently been studied $[154,155]$ using image-based size information and features robust to rotation.

The process flow of counterfeit banknote detection is similar to that of banknote recognition, including strong feature extraction and classification steps, but it requires a sensor responding to specific wavelengths in order to extract anti-counterfeiting features. While high-resolution image sensors and processors may be applied to extract microfine anti-counterfeiting features, such as anti-copier lines or microlettering, they are disadvantageous in terms of economic feasibility, and UV or NIR sensors are commonly used for analyzing anti-counterfeiting features. More recently, counterfeit banknote detection in a mobile environment has been studied $[115,118]$, and a method using data communication with a server has also been presented [115]. Studies investigating counterfeit coin detection $[89,90,156,157]$ mostly use the X-ray fluorescence-based component analysis instead of using visible light.

Serial number recognition is carried out after banknote recognition by determining the position information of the serial number specific to the denomination concerned as the ROI. It requires an image-processing technique capable of segmenting the serial number region from the background and a pattern-matching algorithm that can classify the class of each number/letter efficiently and rapidly. The serial number is a unique piece of information on each banknote, which lends itself well to counterfeit banknote detection. Additionally, if server-based data communication becomes possible for serial number management, it will greatly contribute to counterfeit banknote detection.

Fitness classification is a technique used for sorting banknotes in terms of soiling level and is necessary for ensuring circulation of clean banknotes. Fitness classification is also important from the perspective of counterfeit banknote detection because soiled banknotes tend to broaden the image range applicable to genuine banknotes, thus undermining the performance of banknote recognition and counterfeit perception algorithms. Fitness classification is also carried out in two process steps of feature extraction and classification. Its classification criteria are different from those of banknote recognition, counterfeit banknote detection, and serial number detection in that the results largely depend on the assessor's own judgment. To address such an ambiguous boundary, a method employing a fuzzy system has been studied [138]. There is a need for a system that can freely control and define a fitness boundary.

As such, if the overall process flow of banknote recognition, counterfeit banknote detection, serial number recognition, and fitness classification could be carried out in a refined integral system, such a system would greatly contribute to safe banknote transactions and thus prove beneficial to society.

Acknowledgments: This research was supported by Basic Science Research Program through the National Research Foundation of Korea (NRF) funded by the Ministry of Education (NRF-2015R1D1A1A01056761), and in 
part by the Bio \& Medical Technology Development Program of the NRF funded by the Korean government, MSIP (NRF-2016M3A9E1915855).

Author Contributions: Ji Woo Lee and Kang Ryoung Park studied banknote recognition methods, and wrote paper. Hyung Gil Hong and Ki Wan Kim helped the surveys on serial number recognition and fitness classification.

Conflicts of Interest: The authors declare no conflict of interest.

\section{References}

1. Kim, E.; Turton, T. The next generation banknote project. Bull. Reserve Bank Aust. 2014, 2014, 1-12.

2. Automated Teller Machine. Available online: http://www.moxa.com/vertical_markets/atm/ATMSolution. htm (accessed on 1 October 2016).

3. Money Counters. Available online: http://www.accubanker.com/collections/money-counters (accessed on 1 October 2016).

4. Coin Counting Machines. Available online: http://www.cumminsallison.com/us/en/products/coincounting-machines (accessed on 1 October 2016).

5. Vending Products. Available online: http://www.meigroup.com/asia/vending/vending_products/ (accessed on 1 October 2016).

6. Serial Numbers-Series Year and Serial Number Relationship Table. Available online: https://www. moneyfactory.gov/seriessntable.html (accessed on 1 October 2016).

7. Superdollar. Available online: https://en.wikipedia.org/wiki/Superdollar (accessed on 1 October 2016).

8. Park, Y.H.; Kwon, S.Y.; Pham, T.D.; Park, K.R.; Jeong, D.S.; Yoon, S. A high performance banknote recognition system based on a one-dimensional visible light line sensor. Sensors 2015, 15, 14093-14115. [CrossRef] [PubMed]

9. Pham, T.D.; Park, Y.H.; Kwon, S.Y.; Park, K.R.; Jeong, D.S.; Yoon, S. Efficient banknote recognition based on selection of discriminative regions with one-dimensional visible-light line sensor. Sensors 2016, 16, 328. [CrossRef] [PubMed]

10. Youn, S.; Choi, E.; Baek, Y.; Lee, C. Efficient multi-currency classification of CIS banknotes. Neurocomputing 2015, 156, 22-32. [CrossRef]

11. Liu, Y.; Zeng, L.; Huang, Y. Haar-svm for real-time banknotes recognition. J. Inf. Comput. Sci. 2014, 11, 4031-4039. [CrossRef]

12. Liu, X.; Liu, C. Paper currency CIS image fuzzy enhancement and boundary detection. Appl. Mech. Mater. 2014, 651-653, 2356-2361. [CrossRef]

13. Gai, S.; Liu, P.; Liu, J.; Tang, X. The design of HMM-based banknote recognition system. In Proceedings of the IEEE International Conference on Intelligent Computing and Intelligent Systems, Shanghai, China, 20-22 November 2009; pp. 106-110.

14. Doush, I.A.; Al-Btoush, S. Currency recognition using a smartphone: Comparison between color SIFT and gray scale SIFT algorithms. J. King Saud Univ. Comput. Inform. Sci. 2016. [CrossRef]

15. Ahmadi, A.; Omatu, S.; Kosaka, T.; Fujinaka, T. A reliable method for classification of bank notes using artificial neural networks. Artif. Life Robot. 2004, 8, 133-139. [CrossRef]

16. Gai, S.; Yang, G.; Wan, M. Employing quaternion wavelet transform for banknote classification. Neurocomputing 2013, 118, 171-178. [CrossRef]

17. Hasanuzzaman, F.M.; Yang, X.; Tian, Y. Robust and effective component-based banknote recognition by SURF features. In Proceedings of the 20th IEEE Annual Wireless and Optical Communications Conference, Newark, NJ, USA, 15-16 April 2011; pp. 1-6.

18. Hasanuzzaman, F.M.; Yang, X.; Tian, Y. Robust and effective component-based banknote recognition for the blind. IEEE Trans. Syst. Man Cybern. C Appl. Rev. 2012, 42, 1021-1030. [CrossRef] [PubMed]

19. Kagehiro, T.; Nagayoshi, H.; Sako, H. A hierarchical classification method for US bank notes. In Proceedings of the IAPR Conference on Machine Vision Applications, Tsukuba Science City, Japan, 16-18 May 2005; pp. 206-209.

20. Ahmadi, A.; Omatu, S.; Kosaka, T. A PCA based method for improving the reliability of bank note classifier machines. In Proceedings of the 3rd International Symposium on Image and Signal Processing and Analysis, Rome, Italy, 18-20 September 2003; pp. 494-499. 
21. Ahmadi, A.; Omatu, S.; Kosaka, T. Improvement of the reliability of bank note classifier machines. In Proceedings of the IEEE International Joint Conference on Neural Networks, Budapest, Hungary, 25-29 July 2004; pp. 1313-1316.

22. Omatu, S.; Yoshioka, M.; Kosaka, Y. Reliable banknote classification using neural networks. In Proceedings of the 3rd International Conference on Advanced Engineering Computing and Applications in Sciences, Sliema, Malta, 11-16 October 2009; pp. 35-40.

23. Grijalva, F.; Rodriguez, J.C.; Larco, J.; Orozco, L. Smartphone recognition of the U.S. banknotes' denomination, for visually impaired people. In Proceedings of the IEEE ANDESCON Conference, Bogota, Colombia, 14-17 September 2010; pp. 1-6.

24. Takeda, F.; Omatu, S. A neuro-money recognition using optimized masks by GA. Lect. Notes Comput. Sci. 1995, 1011, 190-201.

25. Toytman, I.; Thambidurai, J. Banknote Recognition on Android Platform. Final Project Report in Standford University. 2010-2011. Available online: http://web.stanford.edu/class/ee368/Project_11/ (accessed on 20 December 2016).

26. Gou, H.; Li, X.; Li, X.; Yi, J. A reliable classification method for paper currency based on LVQ neural network. In Proceedings of the International Conference on Computer Science and Education, Qingdao, China, 9-10 July 2011; pp. 243-247.

27. Sun, N.; Pan, X.; Ma, C.; Cheng, T. A survey on compressed sensing based banknote classification. In Proceedings of the 3rd IEEE International Conference on Signal Processing Systems, Yantai, China, 27-28 August 2011; pp. 60-66.

28. Gai, S.; Liu, P.; Liu, J.; Tang, X. A NN image classification method driven by the mixed fitness function. Comput. Inform. Sci. 2009, 2, 129-136. [CrossRef]

29. Zhang, E.-H.; Jiang, B.; Duan, J.-H.; Bian, Z.-Z. Research on paper currency recognition by neural networks. In Proceedings of the 2nd International Conference on Machine Learning and Cybernetics, Xi'an, China, 2-5 November 2003; pp. 2193-2197.

30. Cao, B.-Q.; Liu, J.-X. Currency recognition modeling research based on BP neural network improved by gene algorithm. In Proceedings of the 2nd International Conference on Computer Modeling and Simulation, Sanya, China, 22-24 January 2010; pp. 246-250.

31. Wu, Q.; Zhang, Y.; Ma, Z.; Wang, Z.; Jin, B. A banknote orientation recognition method with BP network. In Proceedings of the WRI Global Congress on Intelligent Systems, Xiamen, China, 19-21 May 2009; pp. 3-7.

32. Lee, J.-K.; Jeon, S.-G.; Kim, I.-H. Distinctive point extraction and recognition algorithm for various kinds of Euro banknotes. Int. J. Control Autom. Syst. 2004, 2, 201-206.

33. Nastoulis, C.; Leros, A.; Bardis, N. Banknote recognition based on probabilistic neural network models. In Proceedings of the 10th WSEAS International Conference on SYSTEMS, Athens, Greece, 10-12 July 2006; pp. 802-805.

34. Takeda, F.; Nishikage, T. Multiple kinds of paper currency recognition using neural network and application for Euro currency. In Proceedings of the IEEE-INNS-ENNS International Joint Conference on Neural Networks, Como, Italy, 27 July 2000; pp. 143-147.

35. Da Costa, C.M.C. Multiview Banknote Recognition with Component and Shape Analysis. Available online: https://www.researchgate.net/publication/260392128_Multiview_banknote_recognition_with_ component_and_shape_analysis (accessed on 25 November 2016).

36. Bhavani, R.; Karthikeyan, A. A novel method for banknote recognition system. Int. J. Innov. Res. Sci. Eng. Technol. 2014, 3, 269-273.

37. Bhurke, C.; Sirdeshmukh, M.; Kanitkar, M.S. Currency recognition using image processing. Int. J. Innov. Res. Comput. Commun. Eng. 2015, 3, 4418-4422.

38. Danti, A.; Nayak, K. Grid based feature extraction for the recognition of Indian currency notes. Int. J. Latest Trends Eng. Technol. 2014, 4, 337-344.

39. Shyju, S.; Thamizharasi, A. Indian currency identification using image processing. Int. J. Adv. Eng. Manag. Sci. 2016, 2, 344-349.

40. Aggarwal, H.; Kumar, P. Indian currency note denomination recognition in color images. Int. J. Adv. Comput. Eng. Commun. Technol. 2012,1,12-18.

41. Sharma, B.; Kaur, A.; Vipan, K. Recognition of Indian paper currency based on LBP. Int. J. Comput. Appl. 2012, 59, 24-27. [CrossRef] 
42. Manikandan, K.; Sumithra, T. Currency recognition in mobile application for visually challenged. Discovery 2015, 30, 245-248.

43. Verma, K.; Singh, B.K.; Agarwal, A. Indian currency recognition based on texture analysis. In Proceedings of the International Conference on Current Trends in Technology, Ahmedabad, India, 8-10 December 2011; pp. 1-5.

44. Choi, E.; Lee, J.; Yoon, J. Feature extraction for bank note classification using wavelet transform. In Proceedings of the 18th International Conference on Pattern Recognition, Hong Kong, China, 20-24 August 2006; pp. 934-937.

45. Behjat, M.; Moallem, P. Fast and low-cost mechatronic recognition system for Persian banknotes. Int. J. Adv. Robot. Syst. 2014, 11, 44. [CrossRef]

46. Mousavi, S.A.; Meghdadi, M.; Hanifeloo, Z.; Sumari, P.; Arshad, M.R.M. Old and worn banknote detection using sparse representation and neural networks. Indian J. Sci. Technol. 2015, 8, 913-918. [CrossRef]

47. Poor Ahangaryan, F.; Mohammadpour, T.; Kianisarkaleh, A. Persian banknote recognition using wavelet and neural network. In Proceedings of the International Conference on Computer Science and Electronics Engineering, Hangzhou, China, 23-25 March 2012; pp. 679-684.

48. Daraee, F.; Mozaffari, S. Eroded money notes recognition using wavelet transform. In Proceedings of the 6th Iranian Conference on Machine Vision and Image Processing, Isfahan, Iran, 27-28 October 2010; pp. 1-5.

49. García-Lamont, F.; Cervantes, J.; López, A. Recognition of Mexican banknotes via their color and texture features. Expert Syst. Appl. 2012, 39, 9651-9660. [CrossRef]

50. García-Lamont, F.; Cervantes, J.; López, A.; Rodríguez, L. Classification of Mexican paper currency denomination by extracting their discriminative colors. Lect. Notes Artif. Intell. 2013, 8266, 403-412.

51. Hinwood, A.; Preston, P.; Suaning, G.J.; Lovell, N.H. Bank note recognition for the vision impared. Australas. Phys. Eng. Sci. Med. 2006, 29, 229-233. [CrossRef] [PubMed]

52. Springer, K.; Subramanian, P.; Turton, T. Australian banknotes: Assisting people with vision impairment. Bull. Reserve Bank Aust. 2015, 2015, 1-12.

53. Yan, W.Q.; Chambers, J.; Garhwal, A. An empirical approach for currency identification. Multimed. Tools Appl. 2015, 74, 4723-4733. [CrossRef]

54. Gunaratna, D.A.K.S.; Kodikara, N.D.; Premaratne, H.L. ANN based currency recognition system using compressed gray scale and application for Sri Lankan currency notes-SLCRec. World Acad. Sci. Eng. Technol. 2008, 45, 235-240.

55. Ali, A.; Manzoor, M. Recognition system for Pakistani paper currency. World Appl. Sci. J. 2013, 28, $2069-2075$.

56. Frosini, A.; Gori, M.; Priami, P. A neural network-based model for paper currency recognition and verification. IEEE Trans. Neural Netw. 1996, 7, 1482-1490. [CrossRef] [PubMed]

57. Tanaka, M.; Takeda, F.; Ohkouchi, K.; Michiyuki, Y. Recognition of paper currencies by hybrid neural network. In Proceedings of the IEEE International Joint Conference on Neural Networks, Anchorage, AK, USA, 4-9 May 1998; pp. 1748-1753.

58. Omatu, S.; Fujinaka, T.; Kosaka, T.; Yanagimoto, H.; Yoshioka, M. Italian lira classification by LVQ. In Proceedings of the International Joint Conference on Neural Networks, Washington, DC, USA, 15-19 July 2001; pp. 2947-2951.

59. Ali Fattouh, A.M. A non-parametric approach for paper currency recognition. Int. J. Comput. Sci. Softw. Eng. 2015, 4, 121-125.

60. Sarfraz, M. A paper currency recognition system with novel features. In Proceedings of the 2nd International Conference on Artificial Intelligence and Pattern Recognition, Shenzhen, China, 16-18 April 2015; pp. 64-68.

61. Zeggeye, J.F.; Assabie, Y. Automatic recognition and counterfeit detection of Ethiopian paper currency. Int. J. Image Graph. Signal Process. 2016, 2, 28-36. [CrossRef]

62. Jahangir, N.; Chowdhury, A.R. Bangladeshi banknote recognition by neural network with axis symmetrical masks. In Proceedings of the 10th International Conference on Computer and Information Technology, Dhaka, Bangladesh, 27-29 December 2007; pp. 1-5.

63. Debnath, K.K.; Ahdikary, J.K.; Shahjahan, M. A currency recognition system using negatively correlated neural network ensemble. In Proceedings of the 12th International Conference on Computer and Information Technology, Dhaka, Bangladesh, 21-23 December 2009; pp. 367-372. 
64. Hlaing, K.N.N. First order statistics and GLCM based feature extraction for recognition of Myanmar paper currency. In Proceedings of the 31st IIER International Conference, Bangkok, Thailand, 2 August 2015; pp. 1-6.

65. Hassanpour, H.; Farahabadi, P.M. Using hidden Markov models for paper currency recognition. Expert Syst. Appl. 2009, 36, 10105-10111. [CrossRef]

66. Khashman, A.; Sekeroglu, B. Multi-banknote identification using a single neural network. Lect. Notes Comput. Sci. 2005, 3708, 123-129.

67. Rashid, A.; Prati, A.; Cucchiara, R. On the design of embedded solutions to banknote recognition. Opt. Eng. 2013, 52, 093106. [CrossRef]

68. Chiang, Y.-W.; Wang, Y.-C.; Jiang, Y.-Y.; Chang, Y.-H. A bill-detection system based on color and texture analyses. In Proceedings of the 19th IPPR Conference on Computer Vision, Graphics and Image Processing, Taoyuan, Taiwan, 13-15 August 2006; pp. 40-45.

69. Takeda, F.; Nishikage, T.; Matsumoto, Y. Characteristics extraction of paper currency using symmetrical masks optimized by GA and neuro-recognition of multi-national paper currency. In Proceedings of the IEEE International Joint Conference on Neural Networks, Anchorage, AK, USA, 4-9 May 1998; pp. 634-639.

70. Rahman, S.; Banik, P.; Naha, S. LDA based paper currency recognition system using edge histogram descriptor. In Proceedings of the 17th International Conference on Computer and Information Technology, Dhaka, Bangladesh, 22-23 December 2014; pp. 326-331.

71. Yaseri, A.; Anisheh, S.M. A novel paper currency recognition using Fourier mellin transform, hidden Markov model and support vector machine. Int. J. Comput. Appl. 2013, 61, 17-22. [CrossRef]

72. Trupti Pathrabe, A.; Bawane, B.N.G. Paper currency recognition system using characteristics extraction and negatively correlated NN ensemble. Int. J. Latest Trends Comput. 2010, 1, 121-124.

73. Takeda, F.; Nishikage, T.; Omatu, S. Banknote recognition by means of optimized masks, neural networks and genetic algorithms. Eng. Appl. Artif. Intell. 1999, 12, 175-184. [CrossRef]

74. Digman, M.; Elder, C. Mobile Banknote Recognition and Conversion. Available online: https:// stacks.stanford.edu/file/druid:yt916dh6570/Elder_Digman_Foreign_Bill_Recognition.pdf (accessed on 25 November 2016).

75. Jin, Y.; Song, L.; Tang, X.; Du, M. A hierarchical approach for banknote image processing using homogeneity and FFD model. IEEE Signal Process. Lett. 2008, 15, 425-428. [CrossRef]

76. Huffer, K. Genuine U.S. Currency Production, Security Features, and Counterfeiting. Available online: http:/ / www.d93schools.org/userfiles/139/Classes/2288/10_counterfeit_ppt.pdf?id=2689 (accessed on 13 December 2016).

77. Nakamura, C. The Security Printing Practices of Banknotes. Available online: http://digitalcommons. calpoly.edu/cgi/viewcontent.cgi?article=1015\&context=grcsp (accessed on 13 December 2016).

78. How to Detect a Counterfeit Dollar Bill. Available online: https://www1.pasadenaisd.org/ UserFiles/Servers/Server_80688/File/Departments/Business\%20Office/How\%20to\%20Detect\% 20a\%20Counterfeit\%20Dollar\%20Bill.pdf (accessed on 13 December 2016).

79. Know Your Money U.S. Dollars. Available online: http://currencyguide.eu/usd-en/KNOWYOURMONEY. pdf (accessed on 13 December 2016).

80. Machine-Readable Security Features. Available online: http://www.cbr.ru/eng/bank-notes_coins/?Prtid= banknotes_itm\&selBanknote=5r_97\&type=type4 (accessed on 30 December 2016).

81. Security Features. Available online: https://www.innoviasecurity.com/uploads/pdfs/Security-FeaturesReference-Guide-EN---Final.pdf (accessed on 30 December 2016).

82. Euro Banknotes-Security Features. Available online: http://www.new-euro-banknotes.eu/EuroBanknotes/Security-features/FEEL/THE-NEW-\%E2\%82\%AC50 (accessed on 30 December 2016).

83. Yeh, C.-Y.; Su, W.-P.; Lee, S.-J. Employing multiple-kernel support vector machines for counterfeit banknote recognition. Appl. Soft Comput. 2011, 11, 1439-1447. [CrossRef]

84. Bhavani, R.; Karthikeyan, A. A novel method for counterfeit banknote detection. Int. J. Comput. Sci. Eng. 2014, 2, 165-167.

85. Chae, S.-H.; Kim, J.K.; Pan, S.B. A study on the Korean banknote recognition using RGB and UV information. Commun. Comput. Inform. Sci. 2009, 56, 477-484. 
86. Lee, K.-H.; Park, T.-H. Image segmentation of UV pattern for automatic paper-money inspection. In Proceedings of the 11th International Conference on Control, Automation, Robotics and Vision, Singapore, 7-10 December 2010; pp. 1175-1180.

87. Roy, A.; Halder, B.; Garain, U.; Doermann, D.S. Machine-assisted authentication of paper currency: An experiment on Indian banknotes. Int. J. Doc. Anal. Recognit. 2015, 18, 271-285. [CrossRef]

88. Rusanov, V.; Chakarova, K.; Winkler, H.; Trautwein, A.X. Mössbauer and X-ray fluorescence measurements of authentic and counterfeited banknote pigments. Dyes Pigments 2009, 81, 254-258. [CrossRef]

89. Hida, M.; Sato, H.; Sugawara, H.; Mitsui, T. Classification of counterfeit coins using multivariate analysis with X-ray diffraction and X-ray fluorescence methods. Forensic Sci. Int. 2001, 115, 129-134. [CrossRef]

90. Hida, M.; Mitsui, T.; Minami, Y. Forensic investigation of counterfeit coins. Forensic Sci. Int. 1997, 89, 21-26. [CrossRef]

91. Rusanov, V.; Chakarova, K.; Madolev, T. Mössbauer spectroscopy investigation of the properties and stability of dollar bank note pigments. Appl. Spectrosc. 2002, 56, 1228-1236. [CrossRef]

92. Chia, T.H.; Levene, M.J. Detection of counterfeit US paper money using intrinsic fluorescence lifetime. Opt. Express 2009, 17, 22054-22061. [CrossRef] [PubMed]

93. Liu, L.; Ye, Y.; Xie, Y.; Pu, L. Serial number extracting and recognizing applied in paper currency sorting system based on RBF network. In Proceedings of the International Conference on Computational Intelligence and Software Engineering, Wuhan, China, 10-12 December 2010; pp. 1-4.

94. Huber-Mörk, R.; Heiss-Czedik, D.; Mayer, K.; Penz, H.; Vrabl, A. Print process separation using interest regions. Lect. Notes Comput. Sci. 2007, 4673, 514-521.

95. Qian, S.; Zuo, X.; He, Y.; Tian, G.; Zhang, H. Detection technology to identify money based on pulsed eddy current technique. In Proceedings of the 17th International Conference on Automation and Computing, Huddersfield, UK, 10 September 2011; pp. 230-233.

96. Chambers, J.; Yan, W.; Garhwal, A.; Kankanhalli, M. Currency security and forensics: A survey. Multimed. Tools Appl. 2015, 74, 4013-4043. [CrossRef]

97. Paradigm EXC 6700-I. Available online: http://www.paradigmcashsystems.com/para-6700i.html (accessed on 30 January 2017).

98. Bruna, A.; Farinella, G.M.; Guarnera, G.C.; Battiato, S. Forgery detection and value identification of Euro banknotes. Sensors 2013, 13, 2515-2529. [CrossRef] [PubMed]

99. Mahajan, S.; Rane, K.P. A survey on counterfeit paper currency recognition and detection. In Proceedings of the International Conference on Industrial Automation and Computing, Nagpur, India, 12-13 April 2014; pp. 54-61.

100. Aoba, M.; Kikuchi, T.; Takefuji, Y. Euro banknote recognition system using a three-layered perceptron and RBF networks. IPSJ Trans. Math. Model. Appl. 2003, 44, 99-109.

101. Vila, A.; Ferrer, N.; Mantecón, J.; Bretón, D.; García, J.F. Development of a fast and non-destructive procedure for characterizing and distinguishing original and fake Euro notes. Anal. Chim. Acta 2006, 559, 257-263. [CrossRef]

102. Vora, K.; Shah, A.; Mehta, J. A review paper on currency recognition system. Int. J. Comput. Appl. 2015, 115, 1-4.

103. Ismail, M.M.M.; Makone, A.B. An automated recognition of fake or destroyed Indian currency notes using image processing. Int. J. Eng. Sci. Res. Technol. 2014, 3, 273-277.

104. Yadav, B.P.; Patil, C.S.; Karhe, R.R.; Patil, P.H. An automatic recognition of fake Indian paper currency note using MATLAB. Int. J. Eng. Sci. Innov. Technol. 2014, 3, 560-566.

105. Khan, S.; Vadekar, Y.; Sant, S.; Jadhav, M. Analysis and recognition of currency notes. Int. Eng. Res. J. 2016, 2, 479-483.

106. Ambadiyil, S.; Reddy, T.R.S.; Teja, B.R.; Pillai, V.P.M. Banknote authentication using normalized cross correlation method. Discovery 2015, 44, 166-172.

107. Babar, A.; Jawalekar, S.; Yadav, K.; Salunke, D.B. Counterfeit currency detector. Int. J. Tech. Res. Appl. 2015, 3, 106-108.

108. Walke, S.V.; Chandwadkar, D.M. Counterfeit currency recognition using SVM with note to coin exchanger. Int. J. Mod. Trends Eng. Res. 2015, 2, 1356-1360.

109. Sharma, P.; Rai, R. Currency authentication using wireless sensor network. Int. Res. J. Comput. Electron. Eng. 2015, 3, 1-3. 
110. Bhasharkar, S.; Kapse, M.; Kahane, P.; Bahvar, P.; Roy, D. Image processing based feature extraction and verification of Indian currency notes. Int. J. Eng. Technol. Manag. 2015, 2, 59-62.

111. Desai, S.; Kabade, S.; Bakshi, A.; Gunjal, A.; Yeole, M. Implementation of multiple kernel support vector machine for automatic recognition and classification of counterfeit notes. Int. J. Sci. Eng. Res. 2014, 5, 882-886.

112. Kavya, B.R.; Devendran, B. Indian currency detection and denomination using SIFT. Int. J. Sci. Eng. Technol. Res. 2015, 4, 1909-1911.

113. Prasanthi, B.S.; Setty, D.R. Indian paper currency authentication system using image processing. Int. J. Sci. Res. Eng. Technol. 2015, 4, 973-981.

114. Prasanthi, B.S.; Setty, D.R. Indian paper currency authentication system-A quick authentication system. Int. J. Sci. Eng. Res. 2015, 6, 1249-1256.

115. Javheri, S.R.; Padole, S.; Deshmukh, P.; Khade, S. Mobile based application for fake currency detection and recognition. Int. J. Adv. Res. Comput. Commun. Eng. 2016, 5, 149-150.

116. Alshayeji, M.H.; Al-Rousan, M.; Hassoun, D.T. Detection method for counterfeit currency based on bit-plane slicing technique. Int. J. Multimed. Ubiquitous Eng. 2015, 10, 225-242. [CrossRef]

117. Lamsal, S.; Shakya, A. Counterfeit paper banknote identification based on color and texture. In Proceedings of the IOE Graduate Conference, Pulchowk, Nepal, 20-22 November 2015; pp. 160-168.

118. Dewaele, T.; Diephuis, M.; Holotyak, T.; Voloshynovskiy, S. Forensic authentication of banknotes on mobile phones. In Proceedings of the IS\&T International Symposium on Electronic Imaging, San Francisco, CA, USA, 14-18 February 2016.

119. Chang, C.-C.; Yu, T.-X.; Yen, H.-Y. Paper currency verification with support vector machines. In Proceedings of the 3rd International IEEE Conference on Signal-Image Technologies and Internet-Based System, Washington, DC, USA, 16-18 December 2007; pp. 860-865.

120. Chakraborty, T.; Nalawade, N.; Manjre, A.; Sarawgi, A.; Chaudhari, P.P. Review of various image processing techniques for currency note authentication. Int. J. Comput. Eng. Res. Trends 2016, 3, 119-122.

121. Mohamad, N.S.; Hussin, B.; Shibghatullah, A.S.; Basari, A.S.H. Banknote authentication using artificial neural network. In Proceedings of the International Symposium on Research in Innovation and Sustainability, Malacca, Malaysia, 15-16 October 2014; pp. 1865-1868.

122. Qian, J.; Qian, D.; Zhang, M. A digit recognition system for paper currency identification based on virtual instruments. In Proceedings of the International Conference on Information and Automation, Colombo, Sri Lanka, 14-17 December 2006; pp. 228-233.

123. Li, W.; Tian, W.; Cao, X.; Gao, Z. Application of support vector machine (SVM) on serial number identification of RMB. In Proceedings of the 8th World Congress on Intelligent Control and Automation, Ji'nan, China, 6-9 July 2010; pp. 6262-6266.

124. Zhao, T.-T.; Zhao, J.-Y.; Zheng, R.-R.; Zhang, L.-L. Study on RMB number recognition based on genetic algorithm artificial neural network. In Proceedings of the 3rd International Congress on Image and Signal Processing, Yantai, China, 16-18 October 2010; pp. 1951-1955.

125. Feng, B.-Y.; Ren, M.; Zhang, X.-Y.; Suen, C.Y. Extraction of serial numbers on bank notes. In Proceedings of the 12th International Conference on Document Analysis and Recognition, Washington, DC, USA, 25-28 August 2013; pp. 698-702.

126. Feng, B.-Y.; Ren, M.; Zhang, X.-Y.; Suen, C.Y. Automatic recognition of serial numbers in bank notes. Pattern Recognit. 2014, 47, 2621-2634. [CrossRef]

127. Feng, B.-Y.; Ren, M.; Zhang, X.-Y.; Suen, C.Y. Part-based high accuracy recognition of serial numbers in bank notes. Lect. Notes Artif. Intell. 2014, 8774, 204-215.

128. Li, X.; Liu, T.; Li, Y.; Zhang, Z.; Deng, S. Study on recognition algorithm for paper currency numbers based on neural network. Proc. SPIE 2008, 7156, 71560X.

129. Kaur, J.; Aggarwal, M. A LabVIEW approach to detect the theft of Indian currency notes. Int. J. Adv. Res. Electron. Commun. Eng. 2013, 2, 84-88.

130. Arora, N.; Dhillon, N.; Sharma, K. Bank automation system for Indian currency a graphical approach. Int. J. Sci. Emerg. Technol. Latest Trends 2013, 6, 22-28.

131. Arif, M. Image processing based feature extraction of currency notes. Int. Res. J. Eng. Technol. 2016, 3, 2609-2610. 
132. Reel, P.S.; Krishan, G.; Kotwal, S. Image processing based heuristic analysis for enhanced currency recognition. Int. J. Adv. Technol. 2011, 2, 82-89.

133. Geusebroek, J.-M.; Markus, P.; Balke, P. Learning banknote fitness for sorting. In Proceedings of the International Conference on Pattern Analysis and Intelligent Robotics, Putrajaya, Malaysia, 28-29 June 2011; pp. 41-46.

134. Balke, P. From fit to unfit: How banknotes become soiled. In Proceedings of the 4th the International Scientific and Practical Conference on Security Printing Watermark Conference, Rostov-on-Don, Russia, 21-23 June 2011; pp. 21-23.

135. Buitelaar, T. The colour of soil. In Proceedings of the DNB Cash Seminar, Amsterdam, The Netherlands, 28-29 February 2008; pp. 1-23.

136. Balke, P.; Geusebroek, J.-M.; Markus, P. BRAIN ${ }^{2}-$ Machine learning to measure banknote fitness. In Proceedings of the Optical Document Security Conference, San Francisco, CA, USA, 18-20 January 2012; pp. 1-12.

137. Pham, T.D.; Park, Y.H.; Kwon, S.Y.; Nguyen, D.T.; Vokhidov, H.; Park, K.R.; Jeong, D.S.; Yoon, S. Recognizing banknote fitness with a visible light one dimensional line image sensor. Sensors 2015, 15, 21016-21032. [CrossRef] [PubMed]

138. Kwon, S.Y.; Pham, T.D.; Park, K.R.; Jeong, D.S.; Yoon, S. Recognition of banknote fitness based on a fuzzy system using visible light reflection and near-infrared light transmission images. Sensors 2016, 16, 863. [CrossRef] [PubMed]

139. He, K.; Peng, S.; Li, S. A classification method for the dirty factor of banknotes based on neural network with sine basis functions. In Proceedings of the International Conference on Intelligent Computation Technology and Automation, Changsha, China, 20-22 October 2008; pp. 159-162.

140. Sun, B.; Li, J. The recognition of new and old banknotes based on SVM. In Proceedings of the 2nd International Symposium on Intelligent Information Technology Application, Shanghai, China, 21-22 December 2008; pp. 95-98.

141. Kang, D.; Nazari, Z.; Mitsui, Y.; Ozawa, K.; Shoji, N. Multi-class classification of fatigued banknotes by using frequency spectral difference. In Proceedings of the International Technical Conference on Circuits Systems, Computers and Communications, Seoul, Korea, 29 June-2 July 2015; pp. 412-415.

142. Teranishi, M.; Omatu, S.; Kosaka, T. Fatigue level estimation of bill by using supervised SOM based on feature-selected acoustic energy pattern. In Proceedings of the 8th International Conference on Hybrid Intelligent Systems, Barcelona, Spain, 10-12 September 2008; pp. 368-373.

143. Mulmule, D.; Dravid, A. A study of computer vision techniques for currency recognition on mobile phone for the visually impaired. Int. J. Adv. Res. Comput. Sci. Softw. Eng. 2014, 4, 160-165.

144. Shirsath, A.A.; Bharkad, S.D. A review of paper currency recognition system. IOSR J. Comput. Eng. 2013, 10, 71-76. [CrossRef]

145. Bala, N.; Rani, U. A review: Paper currency recognition. Int. J. Emerg. Res. Manag. Technol. 2014, 3, 77-81.

146. Ghosh, R.; Khare, R. A study on diverse recognition techniques for Indian currency note. Int. J. Eng. Sci. Res. Technol. 2013, 2, 1443-1447.

147. Kaur, P.; Singla, I. A survey: Coin recognition techniques using ANN. Int. J. Technol. Res. Eng. 2013, 1, 209-212.

148. Aruna, D.H.; Bagga, M.; Singh, B. A survey on Indian currency note denomination recognition system. Int. J. Adv. Res. Sci. Eng. 2015, 4, 947-956.

149. Pawade, D.; Chaudhari, P.; Sonkamble, H. Comparative study of different paper currency and coin currency recognition method. Int. J. Comput. Appl. 2013, 66, 26-31.

150. Sahu, S.; Verma, T. Identification of paper currency techniques: A survey. Int. J. Sci. Technol. Eng. 2016, 2, 607-612.

151. Chakraborty, K.; Basumatary, J.; Dasgupta, D.; Kalita, J.C.; Mukherjee, S. Recent developments in paper currency recognition system. Int. J. Res. Eng. Technol. 2013, 2, 222-226.

152. Shirsath, A.A.; Bharkad, S.D. Survey of currency recognition system using image processing. Int. J. Comput. Eng. Res. 2003, 3, 36-40.

153. Devi, O.R.; Prasad, J.R.; Rao, B.V.S.; Babu, M.S.; Kumar, L.R.; Prakash, P.R.; Kumar, S.S.; Sirisha, J.; Rani, K.S. Survey on paper currency recognition system. Int. J. Emerg. Trends Technol. Comput. Sci. 2016, 5, 105-108. 
154. Mahajan, S.A.; Gaikwad, C.M. Rotation invariable method for currency coin detection. Int. J. Comput. Sci. Inf. Technol. 2014, 5, 1117-1119.

155. Khashman, A.; Sekeroglu, B.; Dimililer, K. A novel coin identification system. Lect. Notes Control Inform. Sci. 2006, 345, 913-918.

156. Suzuki, M. Development of a simple and non-destructive examination for counterfeit coins using acoustic characteristics. Forensic Sci. Int. 2008, 177, e5-e8. [CrossRef] [PubMed]

157. Gagg, C.R.; Lewis, P.R. Counterfeit coin of the realm-Review and case study analysis. Eng. Fail. Anal. 2007, 14, 1144-1152. [CrossRef] article distributed under the terms and conditions of the Creative Commons Attribution (CC BY) license (http:/ / creativecommons.org/licenses/by/4.0/). 